\title{
Chapter 11 \\ Spatial Response Patterns in Biotic \\ Reactions of Forest Trees and Their \\ Associations with Environmental Variables in Germany
}

\author{
Nadine Eickenscheidt, Heike Puhlmann, Winfried Riek, Paul Schmidt- \\ Walter, Nicole Augustin, and Nicole Wellbrock
}

\subsection{Introduction}

Forest soils show diverse conditions and are subject to natural and anthropogenic changes, as was demonstrated in the previous chapters that evaluated the results of the first National Forest Soil Inventory (NFSI I) and second National Forest Soil Inventory (NFSI II) of Germany. With regard to soil acidification, a slow recovery has been observed since the NFSI I in the 1990s. However, constant high loads of atmospheric nitrogen $(\mathrm{N})$ from industrialization, burning of fossil fuels, traffic and

\author{
N. Eickenscheidt $(\square)$ \\ State Agency for Nature, Environment and Consumer Protection of North Rhine-Westphalia, \\ Recklinghausen, Germany \\ e-mail: nadine.eickenscheidt@lanuv.nrw.de \\ H. Puhlmann \\ Forest Research Institute Baden-Württemberg, Freiburg, Germany \\ e-mail: heike.puhlmann@forst.bwl.de \\ W. Riek \\ University for Sustainable Development and Eberswalde forestry State Center of Excellence, \\ Eberswalde, Germany \\ e-mail: winfried.riek@hnee.de \\ P. Schmidt-Walter \\ Northwest German Forest Research Institute, Göttingen, Germany \\ e-mail: paul.schmidt-walter@nw-fva.de \\ N. Augustin \\ Department of Mathematical Sciences, University of Bath, Bath, UK \\ e-mail: n.h.augustin@bath.ac.uk \\ N. Wellbrock \\ Thünen Institute of Forest Ecosystems, Eberswalde, Germany \\ e-mail: nicole.wellbrock@thuenen.de


intensive agriculture (Berge et al. 1999; Galloway et al. 2008), which are associated with eutrophication and acidification (Aber et al. 1998; de Vries et al. 2014), are still worrying. The nutrition of forest trees and soil vegetation indicated an oversupply of $\mathrm{N}$. Due to the strong increase in carbon $(\mathrm{C}), \mathrm{C} / \mathrm{N}$ ratios in the organic layer and upper mineral soil layers significantly increased. Heavy metals showed a translocation from the organic layer to the upper mineral soil. Furthermore, the modelled time series of drought stress indices and stored soil water available to plants indicated an increase in the intensity of water deficiency since 1990 and a decrease in the number of years characterized by good water supply. Based on these findings, the question of greatest relevance is how forest trees respond to the conditions and changes in forest soils.

In the present chapter, the biotic reactions of forest trees to conditions and changes in forest soils and to environmental conditions in general were examined. The focus was the four main tree species of Germany: Norway spruce (Picea abies (L.) Karst), Scots pine (Pinus sylvestris L.), European beech (Fagus sylvatica L.) and pedunculate and sessile oak (Quercus robur L. and Q. petraea (Matt.) Liebl., considered together), as well as the European silver fir (Abies alba Mill.). Tree defoliation, tree growth and tree nutrition were chosen as biotic indicators of tree vitality. Tree defoliation denotes the loss of needles or leaves in the crown of a tree compared to a local or absolute reference tree with full foliage. Defoliation is assessed as part of the Forest Condition Survey. The Forest Condition Survey represents a basic part of the Forest Monitoring in addition to the NFSI and the Intensive Forest Monitoring. In Germany, the condition of forest trees was recorded first in 1984, and the survey has been conducted annually throughout Germany since 1990 (see Chap. 1). Tree growth is not a part of the Forest Condition Survey and NFSI, but growth rings were evaluated on NFSI plots in some federal states in Germany. Tree nutrition was recorded as an obligatory parameter during both NFSIs (see Chaps. 1 and 9). The following sections deal with (1) the secondary growth response to drought, (2) the definition of defoliation development types and reasons for differences among these types, (3) the definition of forest nutrition types and reasons for differences among these types, as well as (4) the joint evaluation of defoliation development types and forest nutrition types in Germany. The overall aim was to identify regions at risk of tree vitality loss and risk factors. The findings could contribute to choosing appropriate political and management measures to sustain and improve tree vitality.

\subsection{The Secondary Growth Response to Drought}

This section discusses the extent to which the secondary growth of trees is associated with the availability of soil water. For the analysis, drill cores were extracted within the federal states of Baden-Wuerttemberg, Hesse, Lower Saxony, Bremen and Saxony-Anhalt. 197 drill cores were available for spruce, 193 for beech, 30 for fir, 174 for pine and 98 for oak (common and sessile oak). The vast majority of these 



d)
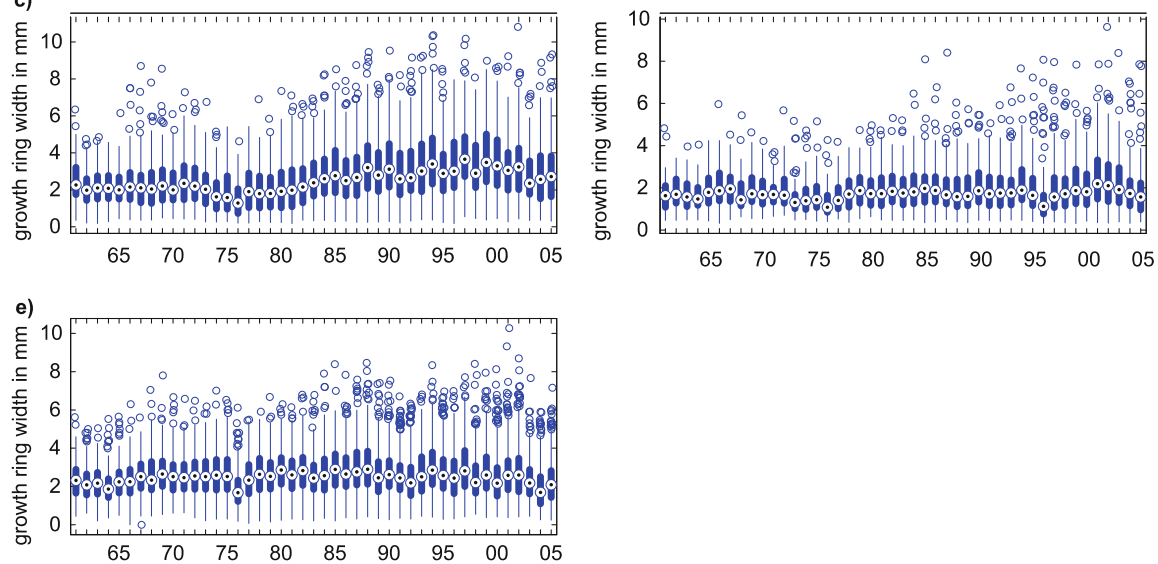

Fig. 11.1 Boxplots of the annual growth ring widths for spruce (a), pine (b), fir (c), oak (d) and beech (e) from 1961 to 2005 . Note that years 1960 to 1990 include measurements only from Baden-Wuerttemberg

drill cores were taken at plots located on brown soils. Soils that were affected by groundwater and stagnant water were not included in further analysis. In BadenWuerttemberg, the widths of annual growth rings were measured for the entire core up to the centre of the stem, whereas in other federal states only the last 15 annual growth rings prior to sampling (2006-2008) were available (Thormann 2014). All further analysis refers to the period from 1961 (beginning of the LWF-Brook90 modelling) to 2005. In total, this led to growth ring measurements from 299 plots with on average 2-3 trees per plot; Fig. 11.1 gives an overview of the time series used. In addition to the time series of the absolute annual growth ring widths, various adjusted growth trends and standardized time series were examined for their correlations with climate and water balance variables. Correlations with absolute annual growth ring widths were greatest; hence, only these are discussed below.

The annual growth ring data were linked to the results of the soil water balance simulations with LWF-Brook90 and other climatic variables (see Chap. 10). A total of 134 different climate and soil water variables were assigned to each annual growth ring for the corresponding NFSI plot and year. Table 11.1 gives an overview of the correlations between the annual growth ring widths and some of the climate and water regime variables. Many of these correlations were statistically significant due 
Table 11.1 Correlations (Pearson coefficient) between annual growth ring widths and characteristic values for climate and soil water availability at the NFSI plots

\begin{tabular}{|c|c|c|c|c|c|c|}
\hline & \multicolumn{5}{|c|}{ Silver } \\
\hline & & Spruce & Pine & fir & Oak & Beech \\
\hline $\begin{array}{l}\text { Minimum temperature in } \\
\text { May }\left[{ }^{\circ} \mathrm{C}\right]\end{array}$ & tmin_may & 0.054 & 0.079 & 0.137 & 0.178 & 0.112 \\
\hline $\begin{array}{l}\text { Mean annual temperature } \\
{\left[{ }^{\circ} \mathrm{C}\right]}\end{array}$ & tmean_y & 0.054 & 0.088 & 0.148 & 0.178 & 0.113 \\
\hline $\begin{array}{l}\text { Temperature sum in veg. } \\
\text { period }\left[{ }^{\circ} \mathrm{C}\right]\end{array}$ & tsum_vp & n.s. & 0.063 & 0.139 & 0.179 & 0.138 \\
\hline Number of days $>5^{\circ} \mathrm{C}[\mathrm{d}]$ & gdd5_y & 0.074 & 0.105 & 0.165 & 0.166 & 0.107 \\
\hline Day degree sum $>5^{\circ} \mathrm{C}\left[{ }^{\circ} \mathrm{C}\right]$ & gdd5_tsum_y & 0.054 & 0.075 & 0.158 & 0.194 & 0.130 \\
\hline $\begin{array}{l}\text { Begin of vegetation period } \\
\text { [Julian day] }\end{array}$ & vp_start & -0.060 & -0.111 & -0.145 & -0.122 & -0.108 \\
\hline $\begin{array}{l}\text { Duration of vegetation peri- } \\
\text { od [d] }\end{array}$ & vp_dauer & 0.056 & 0.103 & 0.130 & 0.121 & 0.114 \\
\hline $\begin{array}{l}\text { Annual precipitation sum } \\
{[\mathrm{mm}]}\end{array}$ & prec_y & n.s. & 0.139 & n.s. & n.s. & 0.049 \\
\hline $\begin{array}{l}\text { Precipitation sum in veg. } \\
\text { period [mm] }\end{array}$ & prec_vp & 0.039 & 0.144 & n.s. & n.s. & 0.167 \\
\hline $\begin{array}{l}\text { Precipitation sum May to } \\
\text { د. July [mm] }\end{array}$ & prec_mayjul & 0.036 & 0.118 & n.s. & 0.090 & 0.177 \\
\hline $\begin{array}{l}\text { 远 Grass reference evapo- } \\
\text { transpiration [mm] }\end{array}$ & et0_vp & 0.029 & n.s. & 0.151 & n.s. & 0.125 \\
\hline $\begin{array}{l}\text { Climatic water balance } \\
{[\mathrm{mm}]}\end{array}$ & kwb_vp & 0.034 & 0.089 & n.s. & n.s. & 0.099 \\
\hline Deep percolation $[\mathrm{mm}]$ & vrfln_vp & n.s. & n.s. & -0.056 & 0.263 & 0.104 \\
\hline $\begin{array}{l}\text { Plant available soil water } \\
0-100 \mathrm{~cm}[\mathrm{~mm}]\end{array}$ & $\mathrm{S}_{\mathrm{p} 0,100 \_\mathrm{y}}$ & n.s. & n.s. & n.s. & 0.289 & 0.127 \\
\hline $\begin{array}{l}\text { Plant available soil water } \\
0-100 \mathrm{~cm}[\mathrm{~mm}]\end{array}$ & $\mathrm{S}_{\mathrm{p} 0,100 \_v p}$ & n.s. & n.s. & n.s. & 0.323 & 0.140 \\
\hline $\begin{array}{l}\text { Plant available soil water } \\
0-10 \mathrm{~cm}[\mathrm{~mm}]\end{array}$ & $\mathrm{S}_{\mathrm{p} 0,10 \_\mathrm{y}}$ & -0.076 & 0.120 & 0.045 & n.s. & 0.106 \\
\hline $\begin{array}{l}\text { शे Plant available soil water } \\
0-10 \mathrm{~cm}[\mathrm{~mm}]\end{array}$ & $\mathrm{S}_{\mathrm{p} 0,10 \_\mathrm{vp}}$ & -0.071 & 0.101 & n.s. & n.s. & 0.164 \\
\hline $\begin{array}{l}\text { क्: Plant available soil water } \\
\text { i0-30 } \mathrm{cm}[\mathrm{mm}]\end{array}$ & $\mathrm{S}_{\mathrm{p}, 1030 \_\mathrm{y}}$ & -0.071 & 0.070 & n.s. & n.s. & 0.089 \\
\hline $\begin{array}{l}\text { Plant available soil water } \\
10-30 \mathrm{~cm}[\mathrm{~mm}]\end{array}$ & $\mathrm{S}_{\mathrm{p}, 1030 \_v p}$ & -0.058 & n.s. & n.s. & 0.185 & 0.126 \\
\hline $\begin{array}{l}\text { Plant available soil water } \\
30-60 \mathrm{~cm}[\mathrm{~mm}]\end{array}$ & $\mathrm{S}_{\mathrm{p}, 3060 \_\mathrm{y}}$ & n.s. & 0.038 & n.s. & 0.259 & 0.124 \\
\hline $\begin{array}{l}\text { Plant available soil water } \\
30-60 \mathrm{~cm}[\mathrm{~mm}]\end{array}$ & $\mathrm{S}_{\mathrm{p}, 3060 \_v p}$ & n.s. & n.s. & n.s. & 0.280 & 0.121 \\
\hline
\end{tabular}


Table 11.1 (continued)

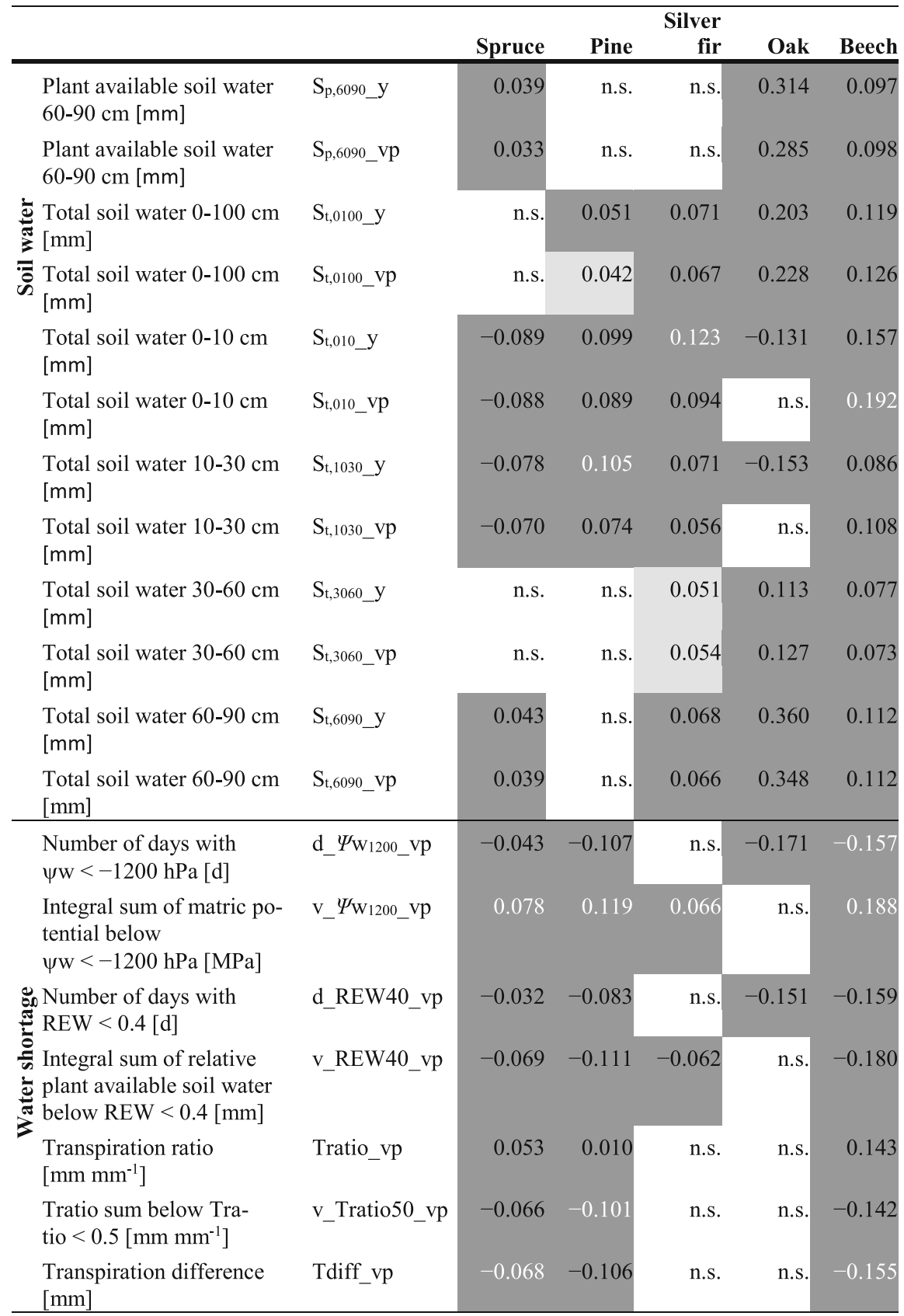

Significance levels of the correlations: dark grey $=p<0.001$, light grey $=p<0.01$, white $=$ not significant; white numbers: covariable in boosted regression trees. Variable ending _y: means/totals over the whole year; _vp: dynamic vegetation period from LWF-Brook90 
to the large sample size, but the correlations between annual growth rings and climate and water regime variables were generally weak; i.e. they statistically differed from zero only by small amounts. In Table 11.1, variables showing very weak correlations for all tree species were omitted for a better overview. There were clear differences between the tree species considered: soil water availability in particular was associated with secondary growth in beech trees. Both the absolute soil water storage $\left(S_{t}, S_{p}\right)$ and the derived water shortage indices were significantly correlated with annual growth ring widths of beech. Oak also showed an association with soil water capacity. Compared to beech, however, lower depths (30-60, $60-90 \mathrm{~cm}$ ) play a greater role. Correlations with water scarcity indices were, in most cases, not significant for oak. However, oak appeared to benefit from more frequent excess of water, as the comparatively strong correlation to seepage values suggested. Among the conifer species, spruce had the strongest correlation between annual growth ring width and soil water retention. Pine showed a stronger correlation with precipitation totals, while the secondary growth of fir was mostly correlated with temperature variables.

The mean values of effective root depth compared to mean values for NFSI or standard depth $(0-100 \mathrm{~cm})$ were not more strongly correlated with annual growth ring widths. Water scarcity indices derived from the modelled soil water contents and matrix potentials were also only partly more strongly correlated than the absolute soil water storage values. Of the water scarcity indices considered, the shortfall of a critical matrix potential in the root space $\left(\mathrm{v}_{-} \Psi_{\mathrm{W}_{1200}} \mathrm{vp}\right)$ showed the closest relation to secondary growth. $v_{-} \Psi \mathrm{w}_{1200}$ vp was highly significantly correlated with annual growth ring widths for all tree species with the exception of oak.

Based on a preselection of possible explanatory variables (Table 11.1), boosted regression trees (BRTs) were used to estimate the annual growth ring widths of a given tree species as a function of climate and soil water variables ( $\mathrm{R}$ version 3.3.1, package "dismo"; Elith et al. 2008). Only variables that were statistically significantly correlated with width of annual growth rings and whose functional correlation depicted in the BRTs was useful and justifiable in soil science and plant physiology were permitted as covariables in the BRTs. The BRTs explained between $19.3 \%$ (spruce) and $61.6 \%$ (oak) of the variance in the measured annual growth ring widths. The explanatory grades of the BRTs for beech $(35.1 \%)$, pine (37.1\%) and fir $(26.0 \%)$ were similar. Figure 11.2 gives an overview of the covariables considered in the BRTs and their relative influence on the explained variance.

Data on soil water capacity and the resulting water shortage indices were included as covariables in all BRT models. As expected, lower soil water availability or more pronounced dry periods led to a decline of annual growth ring widths. This relationship was particularly evident in spruce and beech. Similar reactions were observed by Alavi (2002) and Scharnweber et al. (2011). Together, covariables describing water availability were responsible for $48 \%$ (oak) to $100 \%$ (spruce) of the variance indicated by the BRTs. With the exception for the spruce model, air temperature was another important covariable: an increase in the width of annual growth rings with rising temperatures was observed in the lower temperature ranges, while at higher temperature ranges, a decline or plateau of the annual growth ring widths was 


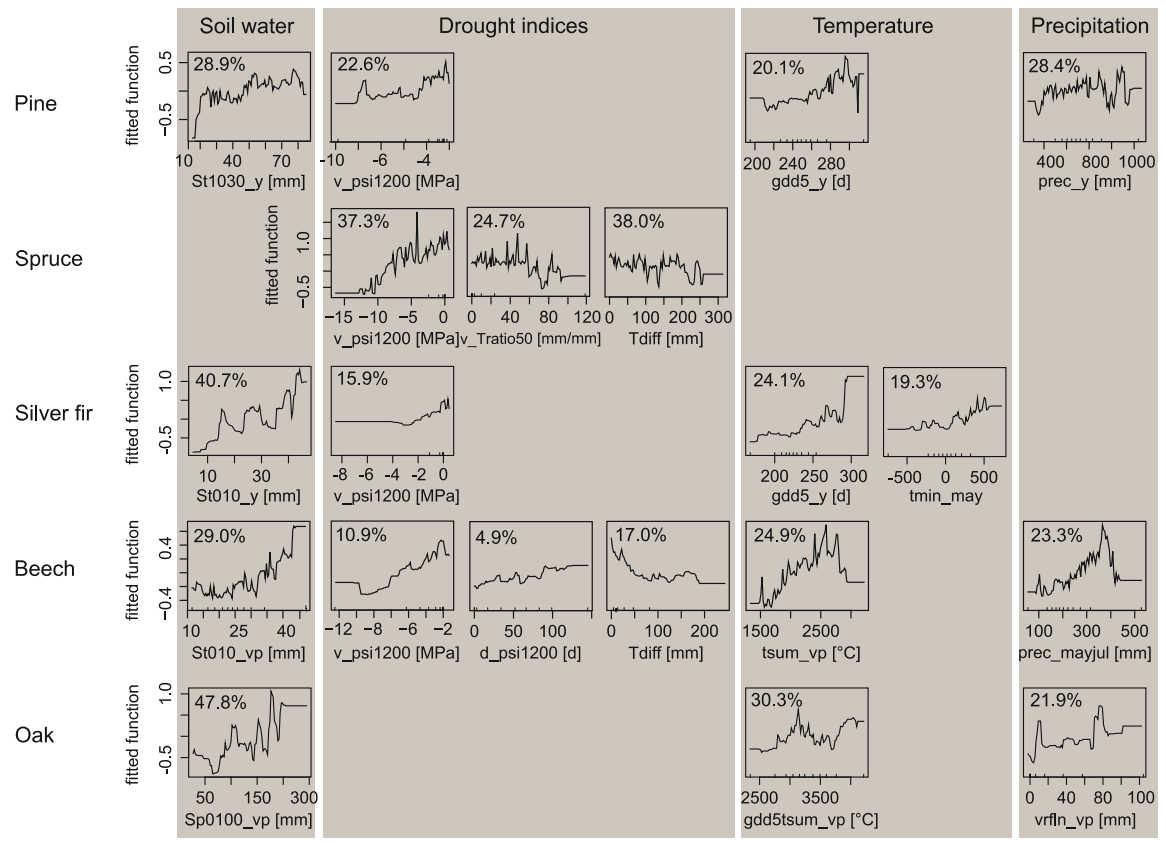

Fig. 11.2 Relationship between prediction of the model ( $y$-axis) and BRT covariables ( $x$-axis) for the various tree species. Percentage: share of the covariable in the variance of annual growth ring widths declared by the BRT

evident for all tree species. Precipitation (for pine and beech) or rather seepage (for oak) was another covariable of the BRTs.

\subsection{Defoliation Development Types and Associated Risk Factors}

The Forest Condition Survey is mandatory across Europe and has been conducted annually on a $16 \times 16 \mathrm{~km}$ grid throughout Germany since 1990. Between 2006 and 2008, the Forest Condition Survey took place on the denser grid of the NFSI II [mainly $8 \times 8 \mathrm{~km}$; with exception of the federal states Rhineland-Palatinate $(4 \times 12 \mathrm{~km}+16 \times 16 \mathrm{~km})$, Saarland $(2 \times 4 \mathrm{~km})$ and Schleswig-Holstein $(8 \times 4 \mathrm{~km})]$. Data from the corresponding denser grids were also available for Baden-Wuerttemberg, Hesse, Lower Saxony and Saxony-Anhalt from 2005 to 2015, for Mecklenburg-Western Pomerania from 1991 to 2015, for Rhineland-Palatinate additionally from 2009 to 2010 and for Saarland from 2009 to 2015. A partial dataset based on the denser grid was also provided by Bavaria from 2009 to 2015. In addition, changes of the grid over time occurred, such as shifts of the initial grid to coincide with the grid of the National Forest Inventory in Bavaria in 2006 and in 
Brandenburg in 2009. Tree defoliation represents the main parameter assessed during the Forest Condition Survey. The estimation of defoliation takes place visually using binoculars, and defoliation is recorded in 5\% classes from $0 \%$ (no defoliation) to $100 \%$ (dead tree). In addition to defoliation, several other parameters (e.g. insect infestation and fructification) are investigated. A detailed description of the survey and quality assurance can be found in Wellbrock et al. (2016) for Germany and in Eichhorn et al. (2016) for Europe. The objectives of this section include (1) identifying regions of similar level and temporal development of defoliation (age-independent defoliation development types) for the four main tree species of Germany and (2) determining reasons for differences in defoliation among defoliation development types. Particular focus was placed on regions at risk of high levels of tree defoliation and risk factors. In Sect. 11.3.1 defoliation development types are defined, in Sect. 11.3.2 variables associated with defoliation are determined, and in Sect. 11.3.3 an integrated analysis of defoliation development types and associated variables is conducted.

\subsubsection{Defining Age-Independent Defoliation Development Types}

In the first step, defoliation development types were defined; these types characterize regions of similar level and temporal development of defoliation. The definition of defoliation development types posed two problems. First, complete time series of defoliation of a plot were necessary. Complete time series could only be available for the $16 \times 16 \mathrm{~km}$ basic grid, if at all. However, changes of this grid have resulted in a loss of many plots, including all of Bavaria and Brandenburg. Hence, the original defoliation data were not very useful for defining defoliation development types for all of Germany. Second, if nevertheless the few complete time series were used for defining defoliation development types, the resulting defoliation development types mainly reflected tree age due to the strong species-specific dependence of defoliation on age (Eickenscheidt et al. 2016, 2019). The aim, however, was to determine age-independent defoliation development types, since regions at risk of high levels of defoliation and risk factors which could be attributed to factors other than age, e.g. human activities, were the primary focus. Thus, age adjustment was necessary to make an age-independent statement about regions at risk. In order to achieve both goals (complete time series and age adjustment) at once, we draw on our spatiotemporal models for defoliation, which were also developed as part of the evaluations of the NFSI II data. A detailed description and results can be found in Eickenscheidt et al. (2016, 2019). Spatio-temporal modelling was conducted by species using generalized additive mixed models (GAMMs; Augustin et al. 2009; Lin and Zhang 1999; Wood 2006a, b): 


$$
\log _{i t} E\left(y_{i t}\right)=\log _{i t}\left(\mu_{i t}\right)=f_{1}\left(\text { stand age }_{i t}\right)+f_{2}\left(\text { easting }_{i}, \text { northing }_{i}, \text { year }_{t}\right)
$$

where $y_{i t}$ is the mean defoliation of one of spruce, pine, beech or oak for sample plot $i=1, \ldots, n$ and for year $t=1, \ldots, 26$, averaged over all trees of the respective species at sample plot $i$. Before averaging, the defoliation class of a single tree was converted into a continuous variable by using the midpoint of the class. The logit link was used since defoliation represents an estimated percentage ranging between 0 and 100; hence defoliation was divided by 100, and the logit link ensured that fitted values were bounded in $(0,1)$. A one-dimensional smooth function of stand age was applied using a penalized cubic regression spline basis for smoothing. A threedimensional smooth function of year and of coordinates (easting and northing of the Gauß-Krüger coordinate system, GK4) was used; this is a tensor product smoother constructed from a two-dimensional marginal smooth for space and a marginal smooth for time (Augustin et al. 2009). The marginal bases were a two-dimensional thin-plate regression spline basis for easting and northing and a cubic regression spline basis for year. The tensor product of the two marginal smooths was chosen so that different penalties for space (metre) and time (years) were used (Wood 2006a, b). A normal distribution was assumed for the error term. The number of trees per plot was considered as weights. The temporal correlation was modelled by a first-order autoregressive-moving average process (ARMA $(1,1)$ ) (Pinheiro and Bates 2000). All evaluations were performed using R 3.4.1 (R Core Team 2017). The R package mgcv (Version 1.8-18; Wood 2017) was utilized for spatio-temporal modelling of defoliation. Although the models were adequate, the model approach has inherent uncertainties. Models generally have model errors, although here a substantial part of the total variance was explained [adjusted $R^{2}$ for spruce, $0.54(n=10182)$; pine, $0.41(n=9252)$; beech, $0.47(n=9283)$; and oak, $0.47(n=6098)$ ]. To take this uncertainty into account, defoliation time series for each plot and tree species were repeatedly simulated (40 times) from the predictive distribution of defoliation, and cluster analysis was then carried out for each of the simulated time series. The predictive distribution was obtained by sampling from the multivariate normal posterior distribution of the model parameters, which itself was obtained by using Bayes' theorem (Augustin et al. 2009; Silverman 1985; Wahba 1983; Wood 2006a, c). Time series were simulated for each plot of the densified grid of 2008 (mainly $8 \times 8 \mathrm{~km}$ ). Stand age was assumed to be 70 years for spruce and pine and 90 years for beech and oak, which roughly corresponded to the weighted median age of the species of the basic grid in 2008. Based on the simulated time series, 40 model-based cluster analyses (R package mclust, version 5.3; Fraley et al. 2017) were conducted for each species. The number of clusters ranged between seven and nine. The assigned 40 clusters per plot and species were summarized in a string and the pairwise string comparison resulted in a string-distance matrix (restricted Damerau-Levenshtein distance; R package stringdist, version 0.9.6.4; van der Loo et al. 2017). Subsequently, a hierarchical cluster analysis was performed using the 
string-distance matrix. Plots having $80 \%$ agreement in the initial 40 cluster analyses were assigned to one cluster using the hierarchical cluster analysis. For the resulting clusters, time trends (median) and Bayesian credible intervals (2.5 and 97.5 percent quantiles) were estimated based on the 40 simulations. Clusters with similar levels of defoliation, identical characteristic peaks and similar time trends were further combined to one cluster. Plots that had not been assigned to a cluster in the first step were then also assigned to clusters in this way. Assignment of these plots was clear, with the exception of four pine and oak plots, which were assigned to the spatially adjacent cluster. Our approach thus led to nine clusters (defoliation development types) for spruce, beech and oak and ten clusters for pine (Fig. 11.3). Finally, these original defoliation development types could be summarised to five broad defoliation development types for each tree species (Fig. 11.3). The summary was based on relatively similar levels of defoliation, identical characteristic peaks and relatively similar time trends. In Fig. 11.3 it can be seen, which of the original clusters were summarized to a broad cluster. The median time trends and Bayesian credible intervals (2.5 and 97.5 percent quantiles) were again estimated based on the 40 simulations, assuming a stand age of 70 years for spruce and pine and 90 years for beech and oak.

Large-scale rather than small-scale spatial defoliation development types were detected for the four main tree species (Fig. 11.3). Clear north-south and east-west differences were found in the defoliation development (Figs. 11.4, 11.5, 11.6, 11.7). For all tree species beginning in 2004, the highest defoliation and strongest increase, respectively, were observed in the defoliation development types that included the south-western part of Germany (e.g. Black Forest). A similar but slightly weaker trend was found in the adjacent north-western regions of Germany (e.g. RhinelandPalatinate, Saarland, Forest of Odes, Spessart). An opposite trend was shown for the defoliation development types that included the north-eastern part of Germany: at the beginning of the 1990s, high defoliation was reported from the eastern part of the North German Lowlands, but defoliation sharply decreased until the mid-1990s and since then has remained relatively constant and on a low level. A trend unlike the trend in south-western Germany was also observed for the defoliation development types including south-eastern Germany. In south-eastern Germany, defoliation was generally high at the beginning of the 1990s but decreased over time. In northwestern Germany, defoliation of all tree species, with the exception of oak, was comparably low and showed only few temporal dynamics. Defoliation development types of pine and oak showed similar spatial distribution. Distribution of defoliation development types of spruce and beech was also similar but slightly different from the types found for pine and oak. Differences mainly occurred in the North German Lowlands (where only one cluster including the north and east of the Lowlands was observed) and southern Germany (where a smaller cluster in south-western Germany but a larger cluster in south-eastern Germany ranging to Saxony was observed). 


\section{Defoliation development types}
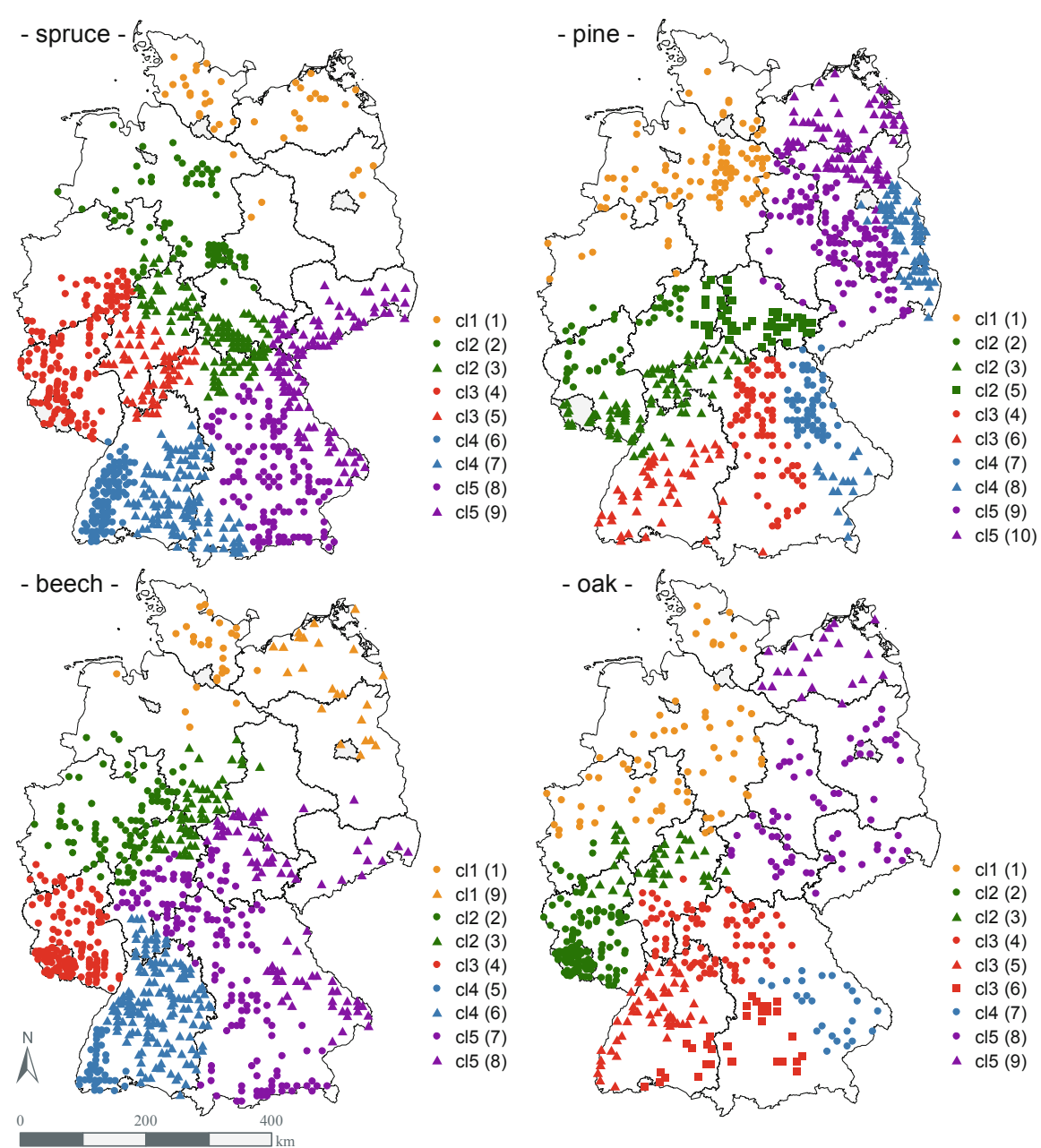

Fig. 11.3 Regional distribution of age-independent defoliation development types (cluster) of spruce (top, left), pine (top right), beech (bottom, left) and oak (bottom, right). The colours indicate the five broad defoliation development types (cl1 to cl5). The combinations of colour and symbol indicate the nine and ten (number in brackets) original defoliation development types, respectively

\subsubsection{Variables Associated with Defoliation}

In a second step, variables associated with defoliation were investigated on a species by species basis. Unlike Sect. 11.4, where discriminant analysis was used to investigate which site-specific and environmental variables were decisive for assignment to a specific nutrition type, variables for defoliation were initially examined 

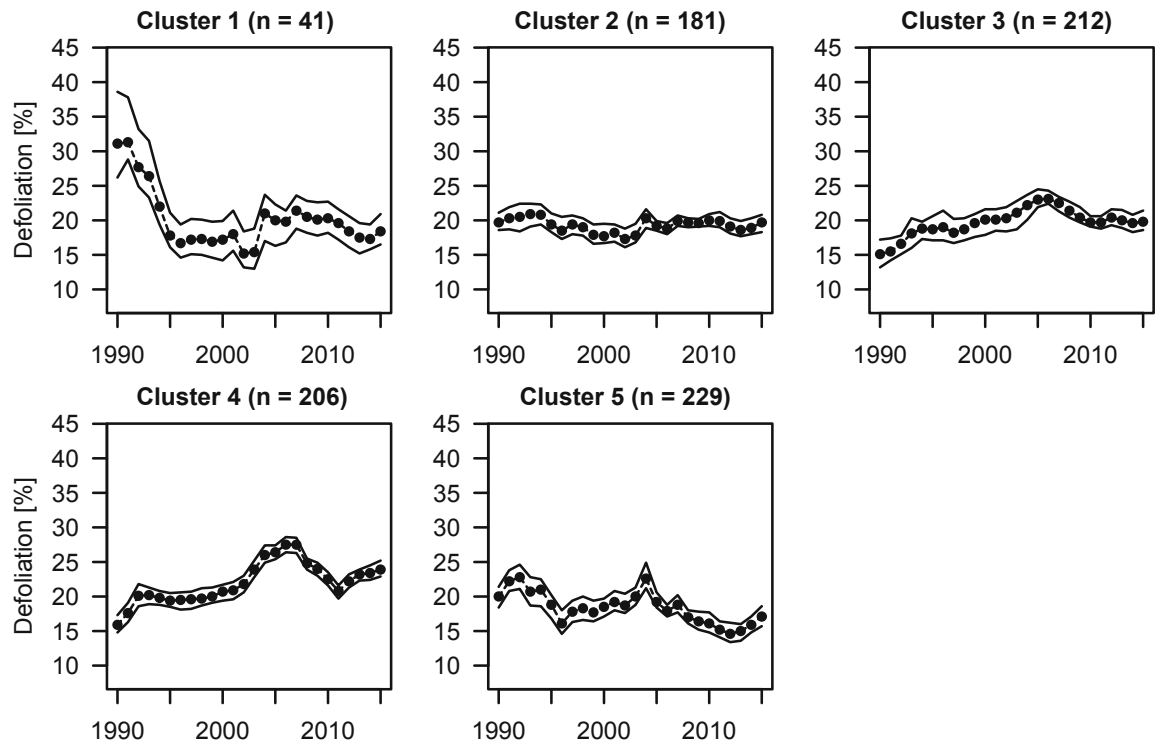

Fig. 11.4 Mean time trends of defoliation and credible intervals of the five broad defoliation development types of spruce. The time trends were estimated based on 40 simulations and assuming a stand age of 70 years. The sample size is given in parenthesis
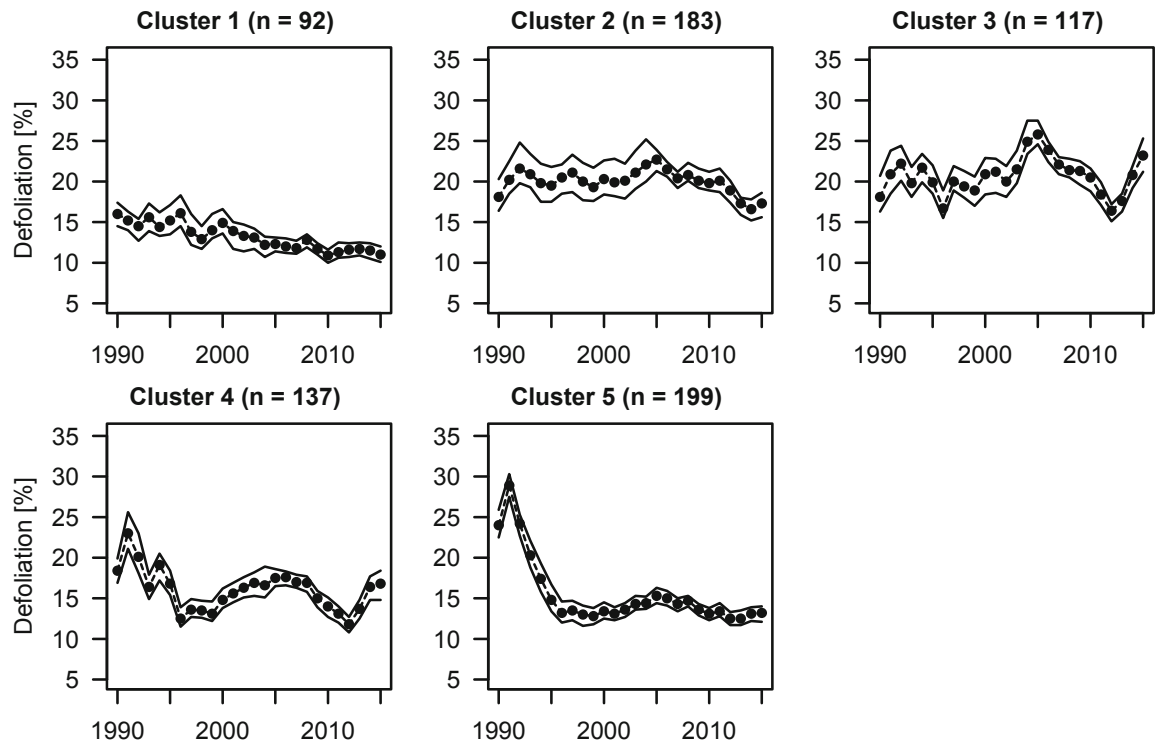

Fig. 11.5 Mean time trends of defoliation and credible intervals of the five broad defoliation development types of pine. The time trends were estimated based on 40 simulations and assuming a stand age of 70 years. The sample size is given in parenthesis 

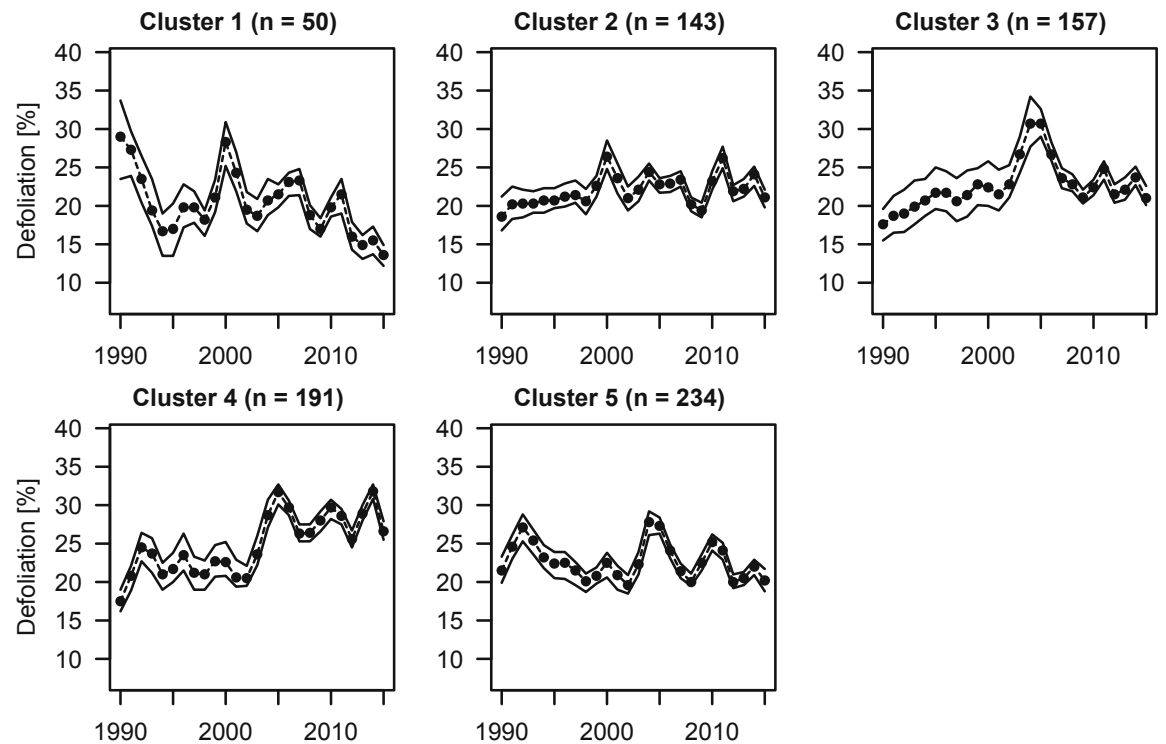

Fig. 11.6 Mean time trends of defoliation and credible intervals of the five broad defoliation development types of beech. The time trends were estimated based on 40 simulations and assuming a stand age of 90 years. The sample size is given in parenthesis
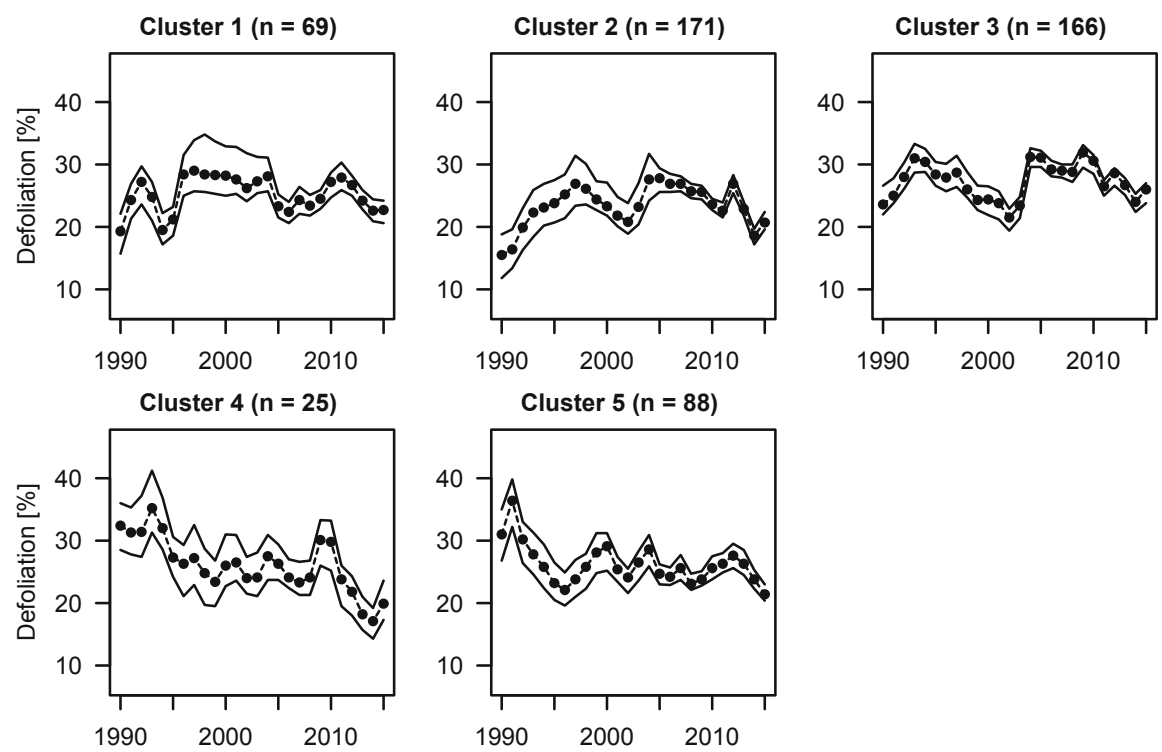

Fig. 11.7 Mean time trends of defoliation and credible intervals of the five broad defoliation development types of oak. The time trends were estimated based on 40 simulations and assuming a stand age of 90 years. The sample size is given in parenthesis 
independently from the defoliation development types since annually varying time series of defoliation formed the basis of these types. As the data are observational, we could not make any inference on causality. Here we have explored which of the available explanatory variables had a statistical effect (rather than a causal effect) on defoliation via model selection. This exploratory analysis resulted in a list of variables that were strongly associated with defoliation and hence might be important in explaining the process leading to defoliation. Associated variables were determined for (1) 1991-2010 (referred to as time series) and (2) the period of the NFSI II (referred to as NFSI period). The two approaches were chosen due to differences in the spatial and temporal resolution and due to differences in the number of available variables. In the first case (time series), the annual defoliation values of the plots of the $16 \times 16 \mathrm{~km}$ basic grid were considered. In the second case (NFSI period), the denser grid of the NFSI II was used, and a mean defoliation value for 2006 to 2008 was calculated for each plot and species. Species-specific defoliation of the plots remained relatively constant between 2006 and 2008, with the exception of beech, where higher defoliation was observed at several plots in 2006, probably due to pronounced fructification. For the time series, fewer variables and plots per year were available, but information was provided annually. Potential influencing variables which were available included stand age, fructification (only from 1999), insect infestation, deposition and weather conditions including deviations from the longterm mean (1961-1990). Lag effects were also considered by using the previous year's values. The soil water balance values regarded for tree growth (see Sect. 11.2) were ultimately not used for defoliation because values were not available for all plots due to shifts in grids and because weather conditions proved equally suitable. For the NFSI period, a large number of variables were available, primarily originating from the NFSI II. In addition to the variables considered for the time series listed above, which were averaged for the time period, additional variables included parameters of soil condition (e.g. C/N ratio, base saturation, stocks of total and exchangeable nutrients, heavy metal stocks), forest nutrition and accompanying information (e.g. liming). GAMMs were used for analyses of association with defoliation. Thus, it was possible to include categorical factors as well as continuous variables and to detect linear as well as non-linear effects. Weights and temporal autocorrelations could also be considered. Examples and a detailed description of the model selection process can be found in Eickenscheidt et al. (2016). In brief, co-linearity among variables was considered, and forward selection and the Bayesian information criterion (BIC; Schwarz 1978) were used for model selection. Model residuals were checked. Stand age represented the most important variable associated with defoliation by far; thus, stand age was included in every model from the beginning.

Defoliation increased species-specific with stand age. For spruce and in particular for beech, defoliation increased nearly linearly, whereas for oak and in particular for pine, defoliation clearly increased until a stand age of approximately 60 years and 40 years, respectively, and only little association of defoliation with age occurred for older trees (Eickenscheidt et al. 2016, 2019). 
Table 11.2 Results of the final models for the four main tree species of Germany (1) for the time series (1991-2010) and (2) for the NFSI period (mean 2006-2008)

\begin{tabular}{|c|c|c|c|c|}
\hline & Spruce & Pine & Beech & Oak \\
\hline \multicolumn{5}{|l|}{ Time series: } \\
\hline Stand age [year] & $* * *$ & $* * *$ & $* * *$ & $* * *$ \\
\hline Fructification [classes] & & & $* * *^{\mathrm{a}}$ & \\
\hline Insect infestation [yes/no] & & $* * *$ & & $* * *$ \\
\hline $\mathrm{NH}_{\mathrm{x}}$ deposition $\left[\mathrm{kg} \mathrm{N} \mathrm{ha}^{-1}\right.$ year $\left.^{-1}\right]$ & & $* * *$ & & \\
\hline temp $\left[{ }^{\circ} \mathrm{C}\right]$ & & $* * *$ & & \\
\hline prec_py $\left[\mathrm{mm} \mathrm{year}^{-1}\right]$ & & & $* * *$ & \\
\hline te(temp_dev, prec_dev) $\left[{ }^{\circ} \mathrm{C}\right]\left[\mathrm{mm}\right.$ year $\left.^{-1}\right]$ & & $* * *$ & $* * *$ & \\
\hline te(temp_py_dev, prec_py_dev) $\left[{ }^{\circ} \mathrm{C}\right]\left[\mathrm{mm}\right.$ year $\left.^{-1}\right]$ & $* * *$ & & $* * *$ & \\
\hline te(temp, temp_dev) $\left[{ }^{\circ} \mathrm{C}\right]\left[{ }^{\circ} \mathrm{C}\right]$ & $* * *$ & & & $* * *$ \\
\hline$R^{2}$ & 0.49 & 0.22 & $0.37 / 0.44^{\mathrm{a}}$ & 0.33 \\
\hline$n$ & 3910 & 3729 & $3121 / 1932^{a}$ & 1748 \\
\hline
\end{tabular}

NFSI period:

\begin{tabular}{|c|c|c|c|c|}
\hline Stand age [year] & $* * *$ & $* * *$ & $* * *$ & $* * *$ \\
\hline Fructification [yes/no] & & & $* *$ & \\
\hline Insect infestation [yes/no] & & & & $* * *$ \\
\hline $\mathrm{N}$ deposition $\left[\mathrm{kg} \mathrm{N} \mathrm{ha}^{-1}\right.$ year $\left.^{-1}\right]$ & $* * *$ & & & \\
\hline temp $\left[{ }^{\circ} \mathrm{C}\right]$ & $* * *$ & & & \\
\hline temp_dev $\left[{ }^{\circ} \mathrm{C}\right]$ & $*$ & & & \\
\hline $\operatorname{prec}\left[\mathrm{mm} \mathrm{year}^{-1}\right]$ & $* *$ & & & \\
\hline te(temp, prec) $\left[{ }^{\circ} \mathrm{C}\right]\left[\mathrm{mm}\right.$ year $\left.^{-1}\right]$ & & $* * *$ & & \\
\hline et $\left[\mathrm{mm}\right.$ year $\left.^{-1}\right]$ & & $* * *$ & $* *$ & $* * *$ \\
\hline et_dev $\left[\mathrm{mm}\right.$ year $\left.^{-1}\right]$ & $* *$ & & $*$ & $* * *$ \\
\hline $\mathrm{C}$ stock of organic layer $\left[\mathrm{t} \mathrm{C} \mathrm{ha}{ }^{-1}\right]$ & $* *$ & & & \\
\hline $\mathrm{C} / \mathrm{N}$ ratio in $0-5 \mathrm{~cm}$ soil depth $[-]$ & $* *$ & $* * *$ & & \\
\hline $\mathrm{C} / \mathrm{P}$ ratio in $0-5 \mathrm{~cm}$ soil depth $[-]$ & & & & $* * *$ \\
\hline $\mathrm{N}$ concentration of needles/leaves $\left[\mathrm{g} \mathrm{kg}^{-1}\right]$ & & & $* * *$ & \\
\hline$R^{2}$ & 0.54 & 0.37 & 0.46 & 0.44 \\
\hline$n$ & 756 & 666 & 463 & 282 \\
\hline
\end{tabular}

The significance of variables associated with defoliation, the coefficient of determination $\left(R^{2}\right)$ of the final model and the sample size $(n)$ are indicated

temp temperature, prec precipitation, et evapotranspiration,_dev deviation from the long-term mean 1961-1990, _py previous year's value, te() tensor product()

$* p<0.05 ; * * p<0.01 ; * * * p<0.001$; ${ }^{a}$ Model only for $1999-2010$

\subsubsection{Time Series}

For the time series, weather conditions had a direct association with annual defoliation of all four tree species (Table 11.2). Deviations of annual mean temperature and precipitation sums from the long-term mean played a major role. Seidling (2007) also reported relationships between defoliation and deviations from long-term means of temperature and precipitation for all four tree species of the German $16 \times 16 \mathrm{~km}$ 


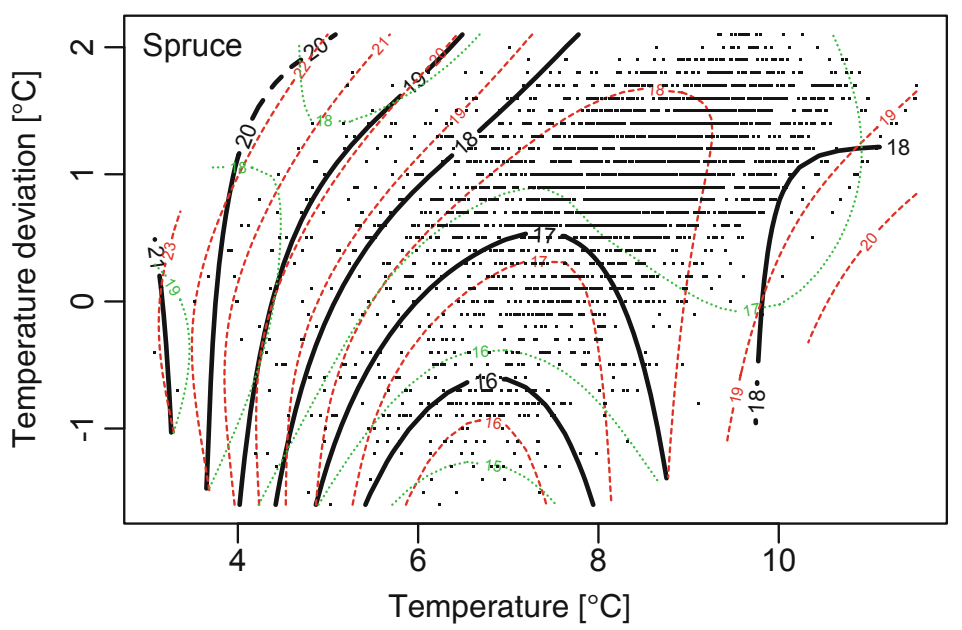

Fig. 11.8 Relationships of temperature and deviations of temperature and their interaction to defoliation of spruce. Black contour lines indicate defoliation in percent. Red and green lines indicate the corresponding standard error of defoliation. Black points reflect the sample distribution

grid. Lagged effects, especially drought in the previous year, and cumulated drought in several preceding years were shown to be closely linked to defoliation in the following year (Ferretti et al. 2014; Klap et al. 2000; Seidling 2007; Zierl 2004); this result was corroborated by our findings.

In the following the results are described for the four tree species, and some figures are presented as examples.

For Norway spruce, mean temperature of the recent year and the deviation of this temperature and the interaction were associated with defoliation of spruce. Higher defoliation in general was found for plots with lower mean temperatures than for plots with higher mean temperatures (Fig. 11.8). Defoliation was highest when positive temperature deviations also occurred on these plots with lower mean temperatures. Lowest defoliation occurred at negative temperature deviations at annual mean temperatures between 6 and $8{ }^{\circ} \mathrm{C}$. Furthermore, previous year's deviations of temperature and precipitation and their interaction had an association with defoliation of the recent year. Years that were cooler and drier compared to the long-term mean resulted in lower defoliation, but warmer and drier years resulted in increased defoliation (compare to beech and Fig. 11.9). Warmer and wetter years were associated with almost no changes in defoliation of spruce. Seidling (2007) also reported higher defoliation of spruce after high temperature (and low rainfall) in the previous and also in the current year, in particular following 2003. For the conifers, higher defoliation especially in the summer 1 year after drought might be attributed to higher needle fall in autumn of the drought year (Solberg 2004). In general, needle loss is still visible years after the event because conifers keep several needle sets.

For Scots pine, recent year's deviations of temperature and precipitation and their interaction showed an association with defoliation. Defoliation of pine was highest 


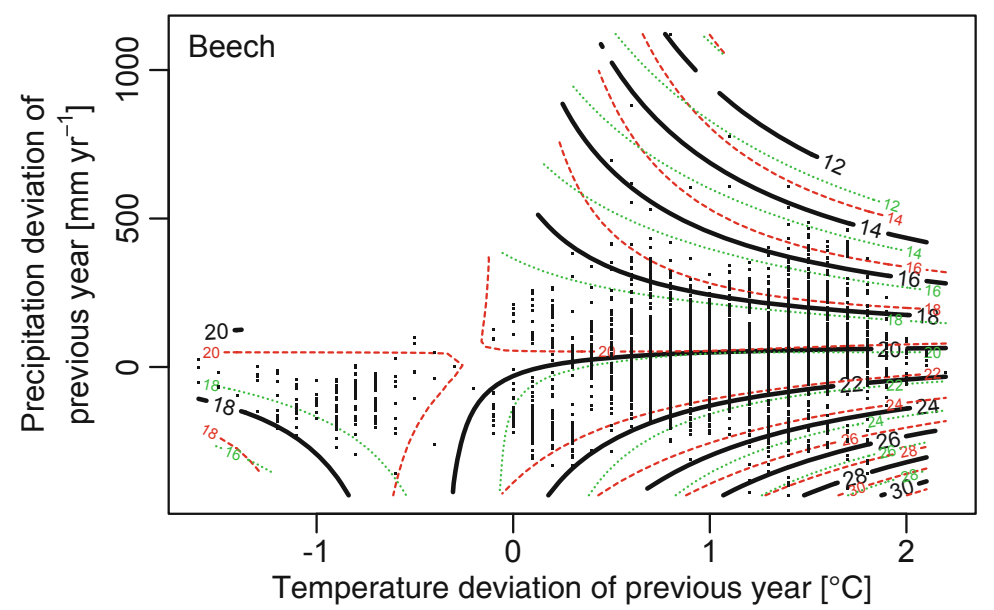

Fig. 11.9 Relationship of previous year's deviations of temperature and precipitation and their interaction with defoliation of beech of the recent year. Black contour lines indicate defoliation in percent. Red and green lines indicate the corresponding standard error of defoliation. Black points reflect the sample distribution

when the temperature deviation was approximately $2{ }^{\circ} \mathrm{C}$ (which corresponded to the highest temperature deviations observed), and precipitation did not deviate. In cooler and wetter years, decreased defoliation of pine was observed. Defoliation further decreased nearly linearly with increasing annual mean temperature. Pine trees in Germany are commonly known to be relatively drought-tolerant (Ellenberg 1996), for example, due to a deep taproot system and early and rapid stomata closure (Seidling 2007 and references therein). However, notable temperature surplus accompanied by precipitation deficits, as observed in 2003, was associated with visible drought stress even in pine trees, which was also reported by Seidling (2007). Besides direct effects of weather, indirect effects were also associated with defoliation. In pine, insect infestation was associated with increased defoliation, another result also documented by Seidling (2001) and Seidling and Mues (2005). Severe infestation is most likely a result of exceptional climatic situations, which favour the development of insects and simultaneously make trees susceptible to infestation. Furthermore, in our study, a negative linear relationship of defoliation and $\mathrm{NH}_{\mathrm{x}}$ deposition was observed.

For European beech, previous year's deviations of temperature and precipitation and their interaction had an association with defoliation of the recent year (Fig. 11.9) similar as found for spruce. However, warmer and wetter years were associated with decreased defoliation of beech which was different from spruce. Furthermore, recent year's deviations of temperature and precipitation and their interaction also showed an association with defoliation of beech but which was different from the association observed for pine. Similar to the effect of deviations of temperature and precipitation of the previous year, defoliation of beech increased in the event of positive temperature deviations and drier conditions, whereas cooler and drier years were associated 
with a decrease in defoliation. Cooler and wetter years also resulted in increased defoliation of beech. Additionally for beech, very low precipitation $(<500 \mathrm{~mm}$ year ${ }^{-1}$ ) and in particular very high precipitation $\left(>1500 \mathrm{~mm} \mathrm{year}^{-1}\right.$ ) of the previous year came along with increased defoliation. The latter was rarely found and was linked to high elevation (e.g. Alps, Black Forest), which was most probably an effect of low temperature and short vegetation period or oxygen deficiency within the soil. Sensitivity of beech to drought is well known, although drought resistance varies among beech populations (Bolte et al. 2016). Beech usually develops from natural rejuvenation and thus is adapted to site conditions. Increased defoliation of beech at low previous year summer or annual precipitation was also reported by Seidling (2006) for Germany and by de Marco et al. (2014) for Europe. Furthermore, aboveaverage previous summer temperature was shown to have a negative association with defoliation of beech in Germany (Seidling 2007; Seidling et al. 2012). The present study additionally revealed that an increase in fructification resulted in increased defoliation of beech (see also Eickenscheidt et al. 2016). Both low precipitation and high temperature of the previous year might be attributed to fructification in the current year, as well as directly to drought stress in the previous year. Weather conditions in the previous early summer determine the production of flower buds and leaf buds, respectively. Hence, fructification is directly linked to higher defoliation but also indirectly because of deterioration of the branch structure as well as development of small leaves. Eichhorn et al. (2005) and Seidling (2007) also reported enhanced defoliation in mast years.

For pedunculate and sessile oak similar as for spruce, the mean temperature of the recent year and the deviation of this temperature and the interaction were associated with defoliation (Fig. 11.10). Lowest defoliation was primarily observed at similar

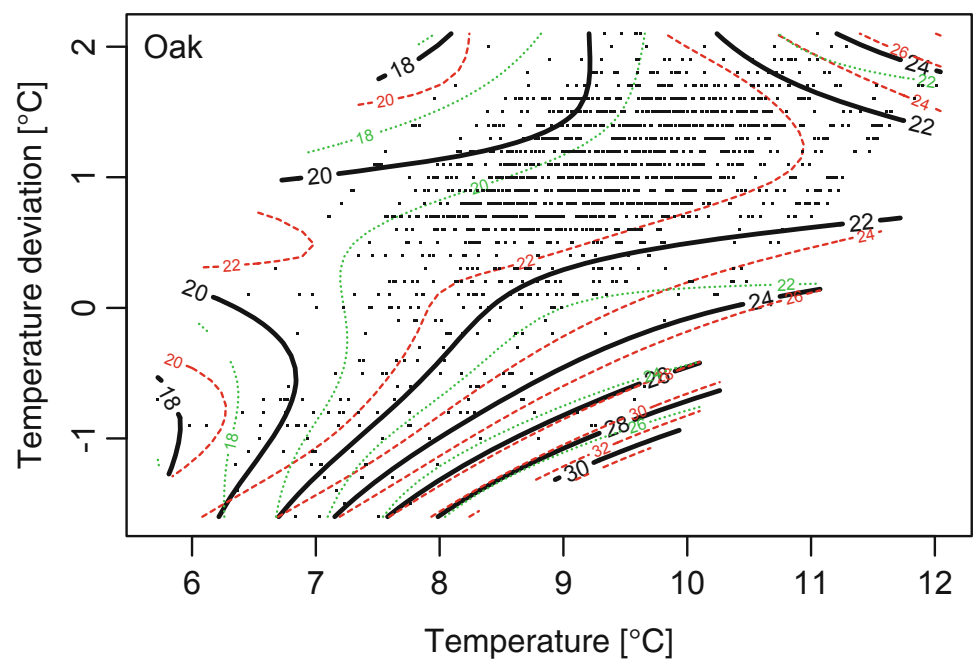

Fig. 11.10 Relationships of temperature and deviations of temperature and their interaction to defoliation of oak. Black contour lines indicate defoliation in percent. Red and green lines indicate the corresponding standard error of defoliation. Black points reflect the sample distribution 
conditions as for spruce. However, mean temperatures were in general higher $\left(6-12{ }^{\circ} \mathrm{C}\right)$ than for spruce $\left(3.5-12{ }^{\circ} \mathrm{C}\right)$. Higher defoliation of oak was found at higher mean temperatures. On plots with higher mean temperatures, positive temperature deviations resulted in increased defoliation, although on plots with average or moderately high mean temperatures, negative deviations of temperature $\left(-1^{\circ} \mathrm{C}\right)$ were associated with the highest defoliations observed for oak. Oak tolerates a wide range of climatic conditions and soil water availability. It can be found on soils with stagnant soil water, but it is also known to be drought-tolerant due to its taproot system and fast stomatic response. However, similar to our findings, several studies have demonstrated a negative impact of high summer temperatures on defoliation of oak in Europe (de Marco et al. 2014; de Vries et al. 2014). At the same time, the observed strong reaction of oak to negative temperature deviations might indicate sensitivity to damage by late frost. Our study further indicated a strong association between defoliation and insect infestation of oak, which was corroborated for Germany by Eichhorn et al. (2005) and on the European scale by Seidling and Mues (2005).

\subsubsection{NFSI Period}

Analyses regarding the NFSI period further revealed soil and nutrient parameters as relevant variables aside from stand age and direct and indirect weather conditions (Table 11.2).

For spruce, a linear decrease in defoliation with increasing stocks of organic $\mathrm{C}$ in the organic layer was observed (not shown). The organic $\mathrm{C}$ in the organic layer reflects the total mass of the organic layer and thus the humus type. A large mass of organic matter might be less susceptible to drying up and protects trees against drought stress, which was also hypothesized by Seidling (2007). Furthermore, defoliation of spruce showed a negative linear relationship to $\mathrm{N}$ deposition (not shown). $\mathrm{N}$ deposition and $\mathrm{N}$ nutrition were generally closely linked and thus, $\mathrm{N}$ deposition might indicate the $\mathrm{N}$ nutrition status. In addition, an increase in defoliation with increasing $\mathrm{C} / \mathrm{N}$ ratios in the $0-5 \mathrm{~cm}$ soil depth beginning at a $\mathrm{C} / \mathrm{N}$ ratio of 30 occurred (Fig. 11.11). Ratios larger than 30 can usually be found in soils having low turnover of organic matter and low $\mathrm{N}$ and other nutrient supply.

Defoliation of pine also exhibited a relationship to the $\mathrm{C} / \mathrm{N}$ ratio. However, the relationship was in contrast to the relationship detected for spruce: the highest defoliation was found at small $\mathrm{C} / \mathrm{N}$ ratios (Fig. 11.11). Soil $\mathrm{pH}$ and exchangeable calcium $(\mathrm{Ca})$ were highly correlated with the $\mathrm{C} / \mathrm{N}$ ratio. Hence, both variables could be used in the GAMM of pine instead of the $\mathrm{C} / \mathrm{N}$ ratio but had less explanatory power than the ratio. Soils with high $\mathrm{pH}$ values, high Ca stocks and high turnover rates (low $\mathrm{C} / \mathrm{N}$ ratios) were accompanied by high defoliation, which might indicate antagonisms between $\mathrm{Ca}$ and other nutrients, especially potassium (K) [Ca-K antagonism; Evers and Hüttl (1992); Zech (1970)]. This antagonistic effect may be enhanced since calcareous soils are often shallow and prone to drought, which exacerbates the K uptake under drought stress (Evers and Hüttl 1992). Riek and 

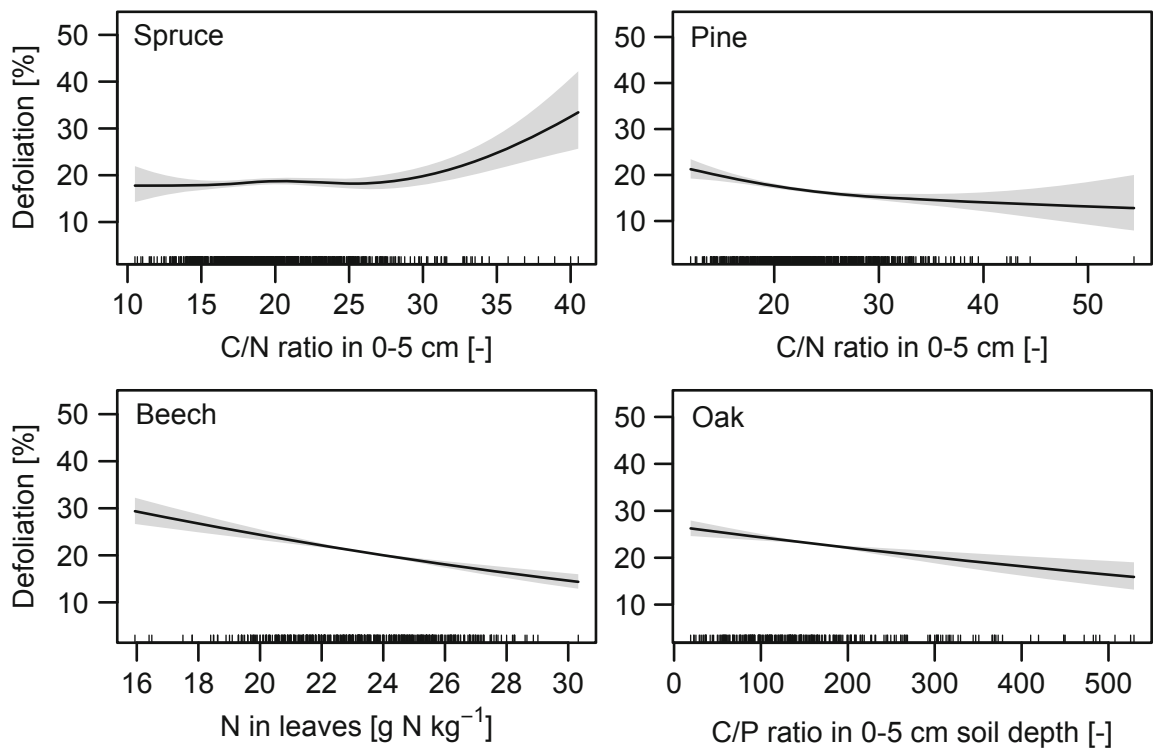

Fig. 11.11 Relationship of $\mathrm{C} / \mathrm{N}$ ratio in the $0-5 \mathrm{~cm}$ soil depth to defoliation of spruce (top, left) and pine (top, right), of $\mathrm{N}$ concentration of leaves to defoliation of beech (bottom, left) and of $\mathrm{C} / \mathrm{P}$ ratio in $0-5 \mathrm{~cm}$ soil depth to defoliation of oak (bottom, right). The lines at the $x$-axis reflect the observed values. The grey-shaded area indicates the $95 \%$ credible interval

Wolff (1999) also reported a negative correlation between defoliation of pine trees of the Level I sites and soil Ca stocks and needle concentrations of Ca, respectively, during the NFSI I. However, these soil conditions also might be an indicator of low mass of organic layer and thus little protection of the soil against drying up.

A negative linear relationship between defoliation and the $\mathrm{N}$ concentration of the leaves existed for beech (Fig. 11.11). Findings by Seidling (2004) for the German Intensive Forest Monitoring plots corroborate a negative correlation between foliar $\mathrm{N}$ supply and defoliation. Low $\mathrm{N}$ nutrition below the normal nutrition range according to Göttlein $\left(2015 ; 19.0-25.0 \mathrm{~g} \mathrm{~N} \mathrm{~kg}^{-1}\right)$ probably resulted in $\mathrm{N}$ deficiency, which might limit tree growth. Interestingly, negative effects of $\mathrm{N}$ surplus on defoliation were not indicated.

For oak, a negative linear relationship between defoliation and the ratio of $\mathrm{C}$ to phosphorus (P) was observed (Fig. 11.11). The $\mathrm{pH}$ value and the organic $\mathrm{C}$ stock in the organic layer could also be used in the GAMM of oak instead of the C/P ratio since the variables were highly correlated. High $\mathrm{pH}$ values, low $\mathrm{C}$ stocks and low $\mathrm{C} / \mathrm{P}$ ratios were accompanied by high defoliation, which again suggested that the relationship presumably was an indicator of the mass of the organic layer and thereby protection against drying up. 


\subsubsection{Integrated Analysis of Defoliation Development Types and Associated Variables}

In the final step, the variables identified in the previous section to be associated with defoliation were further investigated and regarded at the level of the defoliation development types. Results of the previous section highlighted weather conditions and in particular their deviation from the long-term mean as important variables associated with defoliation. Thus, model-based cluster analyses were conducted separately for the time series of relative deviation from the long-term mean of annual mean temperature and annual precipitation sum for Germany. This was done to see whether the resulting clusters coincide with the defoliation development types from Sect. 11.3.1. The results of the model-based cluster analyses were combined by concatenating the cluster indices of the separate analyses to one a string. Subsequently, a hierarchical cluster analysis was performed using the string-distance matrix (see Sect. 11.3.1). The result revealed 11 different weather deviation clusters (Fig. 11.12). Although these weather deviation clusters were more differentiated, they showed similarities to the landscape regions of Germany (Fig. 11.12), which are derived from geomorphological, geological, hydrological, biogeographical and pedological characteristics.

The landscapes and their weather conditions are presented in brief. The North German Lowlands are subdivided into the north-western and the north-eastern Lowlands based on differences in climatic conditions especially regarding precipitation. The Central Upland Range is bordering in the south. The range is also divided into a western part (e.g. Rhenish Slate Mountains, Harz) and an eastern part (e.g. Thuringian Forest, Ore Mountains, Bavarian Forest). To the south(-western) of these low mountain ranges are the Southwest German Scarplands (e.g. Spessart, Franconian and Swabian Albs, Black Forest). In the south the Alpine Foreland and finally the Bavarian Alps follow. The North German Lowlands had on average the highest mean temperature of the landscape regions. The lowest mean temperatures could be found at high altitudes in southern Germany (e.g. Black Forest, Bavarian Forest) and especially in the Alps (data not shown). These regions were also characterized by high precipitation. The north-eastern Lowlands had the lowest mean precipitation, whereas the north-western Lowlands showed a maritime influence. All weather deviation clusters were characterized by a relative mean increase in temperature between 1990 and 2010 compared to the long-term mean (Table 11.3). The mean increase was lowest in the Lowlands (in particular in the eastern part) and highest in the south of Germany, especially in the Alps. Simultaneously, no relative changes in mean precipitation compared to the long-term mean were observed in south-western Germany, whereas precipitation slightly increased in south-eastern Germany and the most in the Lowlands (in particular in the eastern part) (Table 11.4).

The spatial patterns of the defoliation development types of oak (Fig. 11.3) matched well with the landscape regions (Fig. 11.12) and with the weather deviation clusters (Fig. 11.12). Thus, the results of oak are discussed in detail as an example. 


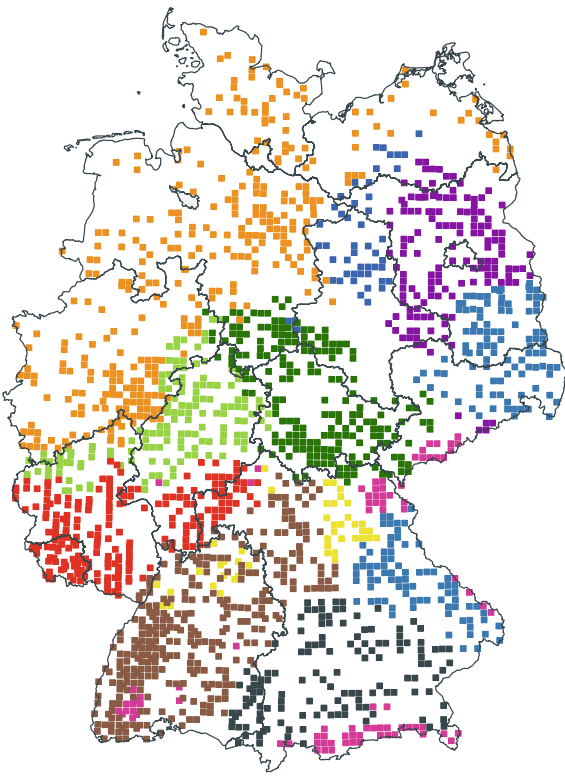

Weather deviation clusters

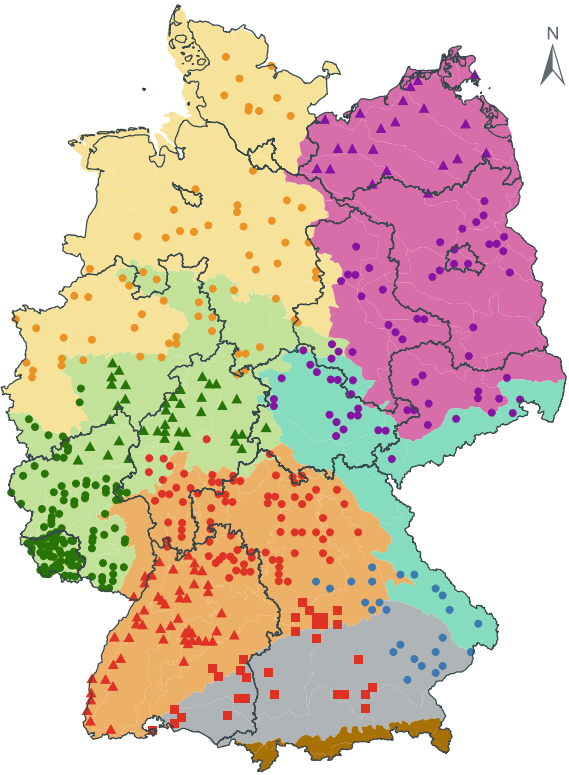

Defoliation development types of oak and landscapes

- $\mathrm{cl} 1(1) \Delta \mathrm{cl} 2(3) \Delta \mathrm{cl} 3(5) \cdot \mathrm{cl} 4(7) \Delta \mathrm{cl} 5(9)$

$\cdot \mathrm{cl} 2(2) \cdot \mathrm{cl} 3(4)=\mathrm{cl} 3(6) \cdot \mathrm{cl} 5(8)$

Fig. 11.12 Regional distribution of the 11 weather deviation clusters (left) and of age-independent defoliation development types of oak (Fig. 11.3) plotted together with the regional distribution of the landscape regions of Germany (right). The weather deviation clusters are based on the relative deviation of annual mean temperature and precipitation sum from the long-term mean (1961-1990). Defoliation development types: The point colours indicate the five broad defoliation development types (cl1-cl5) and the combinations of point colour and symbol indicate the nine original defoliation development types (number in brackets), respectively. Landscapes (background colour): north-western Lowlands (yellow), north-eastern Lowlands (pink), western Central Upland Range (green), eastern Central Upland Range (blue), Southwest German Scarplands (orange), Alpine Foreland (light grey), Alps (brown). (Data source of landscapes: Bundesamt für Naturschutz (BfN), supplied in July 2018)

Oaks grow from the northern Lowlands to the low mountain ranges but rarely in pronounced mountainous or cooler regions. In Sect. 11.3.2 it was shown that a further temperature increase (which was observed on average for all of Germany) resulted in an increase in defoliation in regions having high mean temperatures (Fig. 11.10). Defoliation in the warm Lowlands was on a relatively constant and high level since the mid-1990s (defoliation development type 1 and 5; Fig. 11.7). At the beginning of the time series (especially in 1991), defoliation of type 5 was notably higher than that of type 1. In 1991, the north-eastern Lowlands were notably drier on a relative basis than the north-western Lowlands. However, methodological differences in defoliation assessment after the introduction of the Forest Condition Survey in former eastern Germany, especially in the federal state Mecklenburg-Western 
Table 11.3 Relative deviation [\%] of mean annual temperature from the long-term mean (1961-1990) for the 11 weather deviation clusters

\begin{tabular}{|c|c|c|c|c|c|c|c|c|c|c|c|}
\hline & 1 & 2 & 3 & 4 & 5 & 6 & 7 & 8 & 9 & 10 & 11 \\
\hline 1990 & 17 & 17 & 16 & 18 & 13 & 18 & 14 & 13 & 14 & 15 & 17 \\
\hline 1991 & 3 & 2 & 1 & 3 & 3 & 1 & 2 & 0 & 2 & 1 & 3 \\
\hline 1992 & 14 & 15 & 13 & 16 & 12 & 22 & 14 & 15 & 14 & 16 & 14 \\
\hline 1993 & 1 & 2 & 4 & 2 & 6 & 9 & 7 & 7 & 7 & 5 & 2 \\
\hline 1994 & 15 & 21 & 20 & 15 & 19 & 34 & 24 & 27 & 25 & 23 & 15 \\
\hline 1995 & 8 & 8 & 10 & 7 & 11 & 9 & 9 & 9 & 9 & 9 & 6 \\
\hline 1996 & -14 & -17 & -13 & -16 & -9 & -12 & -9 & -10 & -10 & -13 & -16 \\
\hline 1997 & 8 & 8 & 10 & 7 & 9 & 16 & 10 & 10 & 9 & 8 & 6 \\
\hline 1998 & 9 & 11 & 10 & 10 & 8 & 14 & 12 & 13 & 13 & 13 & 9 \\
\hline 1999 & 18 & 18 & 18 & 18 & 14 & 15 & 14 & 12 & 16 & 15 & 17 \\
\hline 2000 & 19 & 23 & 20 & 20 & 19 & 29 & 22 & 22 & 23 & 23 & 20 \\
\hline 2001 & 9 & 12 & 12 & 8 & 11 & 14 & 13 & 13 & 14 & 11 & 6 \\
\hline 2002 & 15 & 17 & 17 & 13 & 17 & 29 & 19 & 21 & 19 & 18 & 12 \\
\hline 2003 & 13 & 17 & 17 & 12 & 18 & 25 & 19 & 18 & 19 & 16 & 11 \\
\hline 2004 & 9 & 9 & 8 & 9 & 7 & 10 & 9 & 9 & 10 & 9 & 8 \\
\hline 2005 & 12 & 11 & 13 & 11 & 11 & 7 & 9 & 6 & 10 & 9 & 9 \\
\hline 2006 & 18 & 19 & 18 & 19 & 16 & 21 & 17 & 14 & 17 & 16 & 17 \\
\hline 2007 & 20 & 23 & 20 & 22 & 17 & 29 & 20 & 21 & 22 & 24 & 21 \\
\hline 2008 & 15 & 18 & 14 & 19 & 11 & 21 & 15 & 17 & 17 & 19 & 18 \\
\hline 2009 & 12 & 13 & 13 & 13 & 12 & 19 & 13 & 14 & 13 & 15 & 10 \\
\hline 2010 & -6 & -7 & -4 & -5 & -2 & -3 & -1 & 0 & -2 & -2 & -6 \\
\hline
\end{tabular}

Pomerania, cannot be ruled out as a reason for particularly high defoliation at the beginning of the 1990s (Riek and Wolff 1999). Since the mid-1990s defoliation was slightly lower in the eastern part of the Lowlands (defoliation development type 5), which might be attributed to a lesser relative increase in mean temperature and at the same time higher relative increase in precipitation compared to the western part (type 1). In addition, the western part was notably more frequently affected by insect infestation (data not shown). Defoliation development type 2 (western Central Upland Range) and type 3 [Southwest German Scarplands to Alpine Foreland (original defoliation development type 6)] showed similarities in particular regarding the strong increase in defoliation following 2003. In 2003, an exceptional drought and heat occurred in Germany that was most pronounced in south and south-western Germany. Defoliation development type 2 particularly was characterized by a relative increase in drought between 2003 and 2010, whereas type 3 was characterized by a relative increase in temperature. For the latter, highest mean defoliation was found in the last years starting in 2004. Already in 1994, high defoliation at level comparable to that in 2003 was observed for type 3. In 1994 highest relative temperature increase occurred in south Germany. For defoliation development type 4, highest defoliation was found in this year. Since 1994 defoliation on average decreased and was the lowest defoliation observed nowadays. This type could not be 
Table 11.4 Relative deviation [\%] of annual precipitation sums from the long-term mean (1961-1990) for the 11 weather deviation clusters

\begin{tabular}{|c|c|c|c|c|c|c|c|c|c|c|c|}
\hline & 1 & 2 & 3 & 4 & 5 & 6 & 7 & 8 & 9 & 10 & 11 \\
\hline 1990 & 5 & -4 & -1 & 0 & -2 & -3 & -1 & 3 & -5 & -8 & 3 \\
\hline 1991 & -14 & -24 & -24 & -21 & -27 & -15 & -25 & -8 & -25 & -20 & -21 \\
\hline 1992 & 2 & 3 & 5 & 6 & 1 & -2 & 1 & 1 & -3 & -4 & -1 \\
\hline 1993 & 21 & 13 & 10 & 20 & 1 & 7 & 1 & 8 & 3 & 14 & 17 \\
\hline 1994 & 21 & 20 & 12 & 26 & 3 & 3 & 7 & 2 & 3 & 10 & 25 \\
\hline 1995 & 1 & 17 & 6 & -1 & 19 & 21 & 20 & 14 & 27 & 20 & 9 \\
\hline 1996 & -20 & -8 & -17 & -17 & -20 & -6 & -7 & -6 & -13 & -11 & -15 \\
\hline 1997 & -8 & -5 & -15 & -7 & -9 & -8 & -11 & -12 & -11 & -8 & -8 \\
\hline 1998 & 31 & 23 & 17 & 24 & 8 & 9 & 6 & 4 & 17 & 13 & 16 \\
\hline 1999 & 3 & 5 & 1 & -2 & 6 & 16 & 15 & 17 & 6 & -2 & -7 \\
\hline 2000 & 1 & 2 & 5 & 0 & 22 & 9 & 1 & 12 & -3 & -1 & -4 \\
\hline 2001 & 19 & 16 & 11 & 20 & 20 & 19 & 21 & 19 & 37 & 20 & 16 \\
\hline 2002 & 32 & 33 & 24 & 39 & 19 & 26 & 28 & 31 & 32 & 39 & 31 \\
\hline 2003 & -17 & -22 & -22 & -23 & -27 & -22 & -29 & -25 & -28 & -30 & -25 \\
\hline 2004 & 10 & 8 & 1 & 7 & -6 & 0 & -3 & -5 & -2 & 3 & 4 \\
\hline 2005 & 1 & 0 & -5 & 5 & -16 & 5 & -5 & 5 & -6 & 4 & 10 \\
\hline 2006 & -5 & -3 & -7 & -10 & -3 & 2 & 0 & -6 & 3 & -5 & -14 \\
\hline 2007 & 33 & 40 & 22 & 48 & 8 & 15 & 14 & 10 & 17 & 19 & 45 \\
\hline 2008 & 3 & -2 & -10 & 11 & -5 & -4 & -2 & -8 & -2 & 0 & 11 \\
\hline 2009 & 0 & 10 & 1 & 9 & 0 & 2 & 1 & 0 & 5 & 8 & 9 \\
\hline 2010 & 7 & 17 & -2 & 31 & 9 & 6 & 9 & 8 & 15 & 24 & 34 \\
\hline
\end{tabular}

assigned to one landscape but was located in a region of comparably low temperatures and high precipitation. The development of defoliation may indicate that the temperature increase might in general be a benefit for this oak cluster.

Defoliation development types of pine showed spatial distributions and time series of defoliation that were similar to those of oak (Fig. 11.3). Other than for oak, the spatial pattern of defoliation development types of pine matched even better with the weather deviation clusters than with the landscape regions. The division of defoliation development type 4 in two spatially independent areas (Fig. 11.3) also occurred for the weather deviation cluster 10. In addition, the three weather deviation clusters 2, 3 and 4 matched well with the original defoliation development types 5,2 and 3 , which were summarized to the broad defoliation development type 2 .

Spatial distributions of defoliation development types of spruce and beech were similar but deviated from the spatial distributions observed for pine and oak (Fig. 11.3). Defoliation of both species showed a similar trend for the five defoliation development types, although defoliation of beech in general showed more pronounced fluctuations than defoliation of spruce. Moreover, weather conditions were similarly associated with defoliation of both species (see Sect. 11.3.2).

As an example the results for beech will be discussed in the following. Similarities between the spatial patterns of defoliation development types and landscapes 
were not as immediately apparent as for oak but also existed. First of all, slight differences between the western and eastern Lowlands were indicated (original defoliation types 1 and 9). However, beech predominantly grows in moist and cooler regions of the low mountain ranges and the Alpine Foreland and is rarely found in the Lowlands (Fig. 11.3). The eastern Central Upland Range was covered well by the original defoliation development type 8. The western Central Upland Range was also covered well but by two different broad defoliation development types (types 2 and 3). The spatial distribution of type 3, which reflects the federal states Rhineland-Palatinate and Saarland, also roughly existed for the weather deviation clusters (cluster 5; Fig. 11.12). Regarding south Germany, again a prominent change of defoliation development types occurred along the border of two federal states (Baden-Wuerttemberg and Bavaria). Again, this spatial distribution was also partly present in the weather deviation clusters (clusters 6 and 8).

Differences among the five broad defoliation development types of beech regarding time series of precipitation and temperature deviations from 1990 to 2010 are exemplarily presented (Fig. 11.13). Time series of all clusters had notable positive temperature deviations from 1997 to 2009, whereas no systematic deviations occurred for precipitation. The year 1996 was exceptionally cold and dry, and the year 2003 was exceptionally warm and dry throughout Germany. Both events resulted in increased defoliation. However, the intensities differed within clusters.
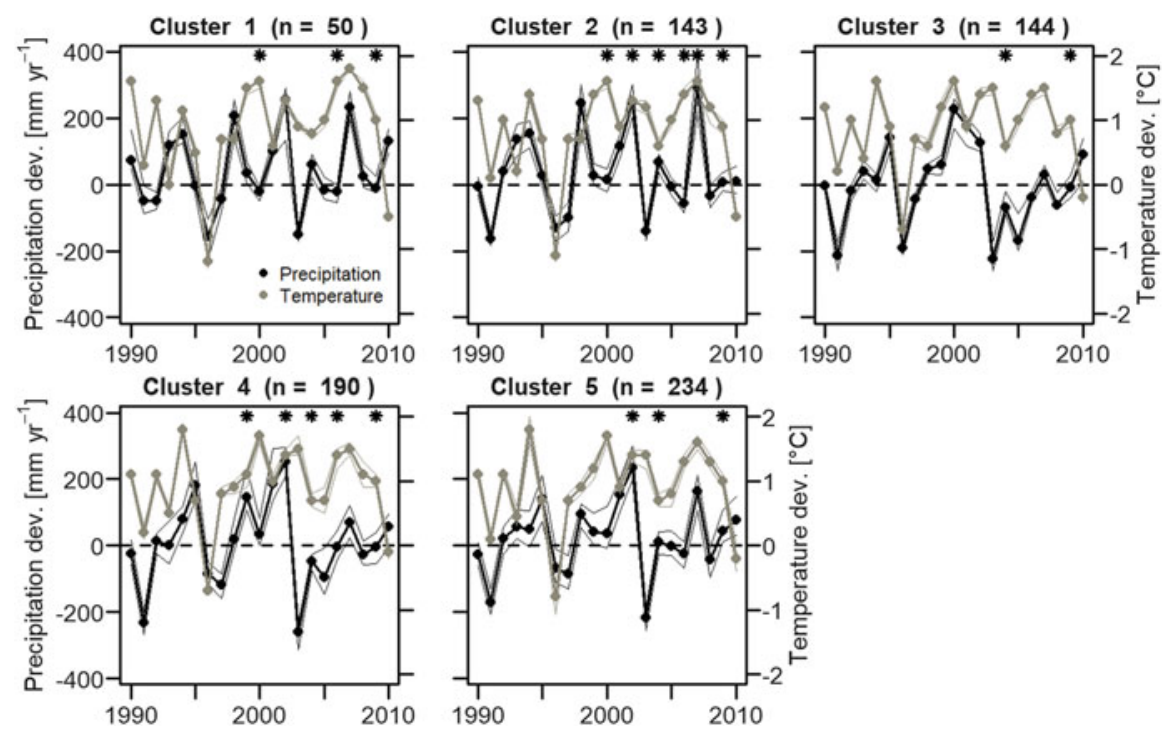

Fig. 11.13 Deviations of precipitation and temperature from the long-term mean 1961-1990 for the five defoliation development types of beech. The median and the intervals representing the 25 and 75 percent quantiles are shown. Fructification of beech in $50 \%$ of plots or more for one cluster is indicated by a star beginning in 1999. The dashed line represents the line of no deviation. The sample size is given in parenthesis 
At the beginning of the 1990s, highest defoliation of beech was observed for defoliation development type 1 . For type 1, the year 1990 was very warm compared to the long-term mean and compared to the other clusters. The conditions at the end of the 1980s and beginning of the 1990s might be the reason for the observed high defoliation, but methodological differences presumably played a role as well. Deviations of temperature and precipitation for defoliation development types 1 and 2 followed a similar pattern, but positive temperature deviations were slightly lower and positive precipitation deviations were slightly higher for type 2. Defoliation development type 2 showed relatively constant mean defoliation between 1990 and 2015, whereas type 1 showed more fluctuation. Both types were characterized by the defoliation peak in 2000 that followed the notable positive temperature deviations at average precipitation in the consecutive years 1999 and 2000. These weather conditions were only observed in the regions of types 1 and 2. In 2000, pronounced fructification additionally occurred for beech of both types. The year 2003 featured positive temperature deviations of on average $1{ }^{\circ} \mathrm{C}$ and a notable negative deviation of precipitation of more than $100 \mathrm{~mm}$ per year for these types. These extreme conditions were accompanied by fructification and a defoliation peak in 2004, which however was lower than the peak in 2000. In contrast, defoliation development types 3 to 5 were characterized by pronounced fructification and high defoliation in 2004, most likely because the deviations of temperature increase and precipitation decrease in 2003 were notably extremer in south and south-western Germany. The highest negative deviation of precipitation accompanied by a high positive deviation of temperature occurred for type 4. In 2004, the greatest increase in defoliation was also observed for this type. Similar to type 3, extreme weather conditions were observed again in the subsequent years. However, beech of type 4 had additionally recurring pronounced fructification, and defoliation remained on the highest level observed for all defoliation development types. In summary, exceptional high temperatures were primarily associated with high defoliation of beech in the recent year, whereas the combination of high temperature and drought was mainly associated with high defoliation in the next year. However, the direct impact of weather was most likely overimposed by the impact of fructification (indirect weather effect).

Significant differences ( $p<0.0001$, ANOVA) among defoliation development types were further observed regarding the key soil parameters identified to be associated with defoliation (see Sect. 11.3.2). The defoliation development types representing south-western Germany had the lowest $\mathrm{C}$ stock and thus mass of the organic layer (spruce, type 4), the lowest $\mathrm{C} / \mathrm{N}$ ratio (pine, type 3 ), the lowest $\mathrm{N}$ concentration of leaves of beech during the NFSI II (beech, type 4) and also the lowest C/P ratio (oak, type 3) (Fig. 11.14).

In conclusion, weather conditions and in particular deviations of temperature and precipitation from the long-term mean explained a large proportion of the differences among defoliation development types of the four tree species. An adaption of forest stands to the long-term average of the local water balance is generally assumed (Zierl 2004 and literature therein); hence, it is obvious that deviations might affect tree vitality. However, in part, defoliation of trees reacted differently to weather 

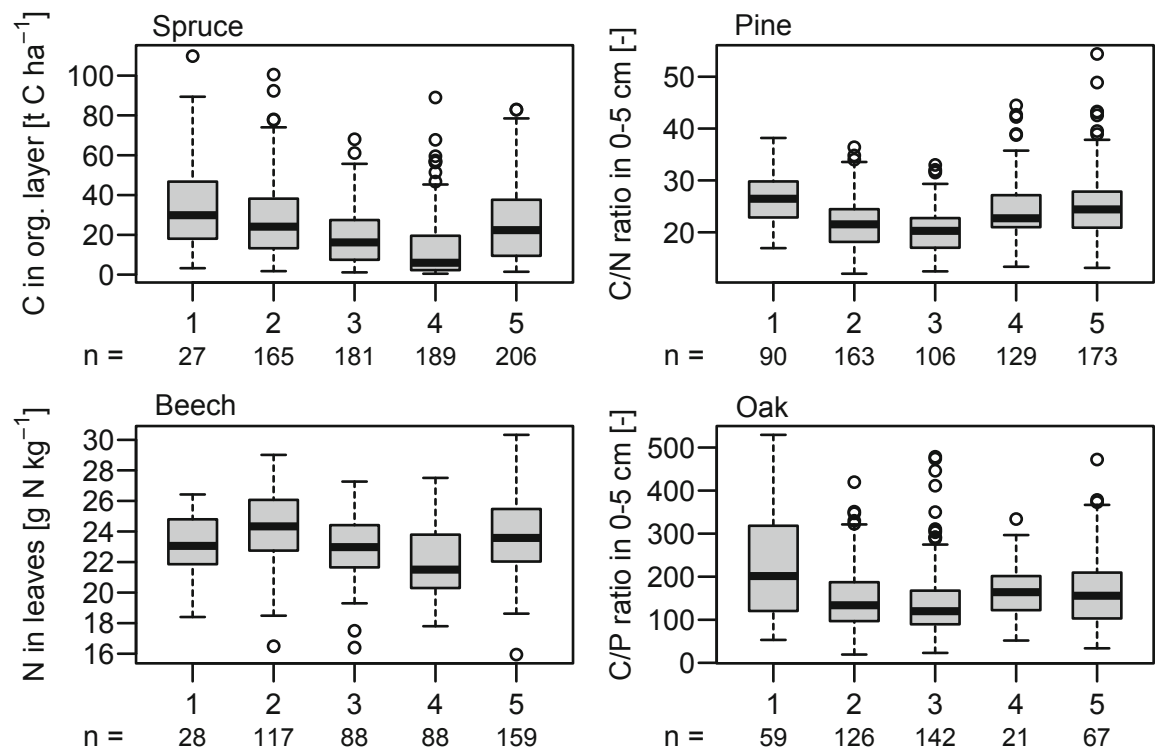

Fig. 11.14 Boxplots of $C$ stock in the organic layer for spruce (top, left), $C / N$ ratio in the $0-5 \mathrm{~cm}$ soil depth for pine (top, right), $\mathrm{N}$ concentration of leaves of beech (bottom, left) and $\mathrm{C} / \mathrm{P}$ ratio in the $0-5 \mathrm{~cm}$ soil depth for oak (bottom, right) for the five defoliation development types of each species

conditions, possibly as consequence of tree species, provenance and differences in other stand conditions. Extraordinarily high temperature deviations of approximately $1.5^{\circ} \mathrm{C}$ and more and in particular when accompanied by extraordinarily high negative precipitation deviations were associated with increased defoliation of all species most likely due to drought stress. These conditions have cumulatively occurred since 2003 especially in south-western Germany. Anders et al. (2004) also corroborated this result, although all of Germany was affected by drought stress in 2003: the highest water deficit calculated as the difference between the climatic water budget of 2003 and the long-term water budget of the reference period 1961-1990 occurred in south-western Germany. Hilly and mountainous areas as, e.g. found in large areas of south-western Germany, are further often characterized by shallow and stony soils, which have low water storage capacity and hamper deep rooting. Additionally, in south-western Germany, low mass of the organic layer was frequently found, which might increase drying up of the soil. In contrast, generally deeper soils and thicker organic layers could be found in the North German Lowlands. Drought stress was detected as the most important risk factor associated with high defoliation. In addition to variables indicating drought stress, fructification of beech, insect infestation (pine, oak) as well as deficiencies in $\mathrm{N}$ nutrition proved to be other stress factors associated with high defoliation. South-western Germany emerged as the area with greatest risk of defoliation, most likely due to drought stress in recent years. However, areas being prone to drought stress due to pedological 
conditions generally represent areas with risk of high defoliation in particular with regard to climate change.

\subsection{Defining Forest Nutrition Types}

The nutritional status of trees can be interpreted as an integrative overall expression of the site-specific water and nutrient supply and the influence of climate and deposition. Below, we assume that at a given site with given environmental conditions, there are identifiable nutritional categories specific to tree species. According to Göttlein (2015), classes can be assigned on the basis of levels of element concentrations in needles and leaves, and, in particular, trees can be assessed for deficiency or surplus of specific elements (see Chap. 9). Typification of the nutritional situation goes beyond classification of the levels of individual elements and collates specific combinations of element supplies. With this approach, we provide definitions for nutrition types for the tree species Norway spruce (Picea abies (L.) H. Karst.), Scots pine (Pinus sylvestris L.), European beech (Fagus sylvatica L.) and pedunculate (Quercus robur L.) and sessile oak (Quercus petraea (Matt.) Liebl.) by analysing the level of five key elemental nutrients ( $\mathrm{Ca}, \mathrm{Mg}, \mathrm{K}, \mathrm{P}$ and $\mathrm{N}$ ) according to Göttlein (2015). For operational reasons, the categories "latent deficiency" and "deficiency", as well as "normal" and "surplus", are pooled. The distinction between normal and surplus nutrition was maintained only for the element nitrogen due to the special considerations for nitrogen (see Chap. 9). In contrast to element-specific classification of the nutrition data, this approach is thus based on simultaneous analysis of multiple key nutrients. Defined nutrition types and their frequencies in the NFSI II sampling data are presented in Table 11.5. Combinations of classifications with a sample size of $n<10$ were not considered and are not listed in the table. Thus, there are 9 different nutrition types for spruce, 10 for Scots pine, 13 for beech and 6 for oak. Assignment to a nutrition type varied by tree species: 91\% (spruce), $86 \%$ (pine, beech) and $76 \%$ (oak) of all plots that were studied could be assigned to one of the nutrition types defined in Table 11.5. These are arranged in the table by species and according to decreasing frequency. The codes presented in Table 11.5 are also used in the descriptions of the identified types in the text that follows.

The most frequent nutrition type for spruce was characterized by an adequate supply of all the key nutrients $(\mathrm{Ca} 0 / \mathrm{K} 0 / \mathrm{Mg} 0 / \mathrm{P} 0 / \mathrm{N} 0)$. The second most common type featured a surplus of $\mathrm{N}$ but otherwise a balanced nutrient supply $(\mathrm{Ca} 0 / \mathrm{K} 0 / \mathrm{Mg} 0 /$ $\mathrm{P} 0 / \mathrm{N}+$ ). According to frequency of occurrence, there followed sites with deficiencies of $\mathrm{K}(\mathrm{Ca} 0 / \mathrm{K}-/ \mathrm{Mg} 0 / \mathrm{P} 0 / \mathrm{N} 0)$ and $\mathrm{P}(\mathrm{Ca} 0 / \mathrm{K} 0 / \mathrm{Mg} 0 / \mathrm{P}-/ \mathrm{N} 0)$. Combined with a deficiency of $\mathrm{K}$ and surplus of $\mathrm{N}(\mathrm{Ca} 0 / \mathrm{K}-/ \mathrm{Mg} 0 / \mathrm{P} 0 / \mathrm{N}+)$, deficiencies of both $\mathrm{P}$ and $\mathrm{N}$ $(\mathrm{Ca} 0 / \mathrm{K} 0 / \mathrm{Mg} 0 / \mathrm{P}-/ \mathrm{N}-), \mathrm{P}$ and $\mathrm{K}(\mathrm{Ca} 0 / \mathrm{K}-/ \mathrm{Mg} 0 / \mathrm{P}-/ \mathrm{N} 0)$ and $\mathrm{P}, \mathrm{K}$ and $\mathrm{N}(\mathrm{Ca} 0 / \mathrm{K}-/$ $\mathrm{Mg} 0 / \mathrm{P}-/ \mathrm{N}-$ ) were less common.

For the other tree species, the most common nutrition type was the type featuring $\mathrm{N}$ surplus (pine, oak) and the type featuring $\mathrm{P}$ deficiencies (beech). The nutrition type with an adequate supply of all key nutrients ranked in second place for pine, oak and 
Table 11.5 Nutrition types based on the combined classification of the levels of $\mathrm{Ca}, \mathrm{K}, \mathrm{Mg}, \mathrm{P}$ and $\mathrm{N}$ according to Göttlein (2015)

\begin{tabular}{|c|c|c|c|c|c|c|c|}
\hline & $\mathbf{C a}$ & $\mathbf{K}$ & Mg & $\mathbf{P}$ & $\mathbf{N}$ & Code & $\mathrm{n}$ \\
\hline \multirow{9}{*}{ 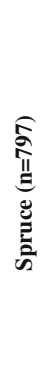 } & & & & & & $\mathrm{Ca} 0 / \mathrm{K} 0 / \mathrm{Mg} 0 / \mathrm{P} 0 / \mathrm{N} 0$ & 271 \\
\hline & & & & & & $\mathrm{Ca} 0 / \mathrm{K} 0 / \mathrm{Mg} 0 / \mathrm{P} 0 / \mathrm{N}+$ & 178 \\
\hline & & & & & & $\mathrm{Ca} 0 / \mathrm{K}-/ \mathrm{Mg} 0 / \mathrm{P} 0 / \mathrm{N} 0$ & 93 \\
\hline & & & & & & $\mathrm{Ca} 0 / \mathrm{K} 0 / \mathrm{Mg} 0 / \mathrm{P}-/ \mathrm{N} 0$ & 67 \\
\hline & & & & & & $\mathrm{Ca} 0 / \mathrm{K}-/ \mathrm{Mg} 0 / \mathrm{P} 0 / \mathrm{N}+$ & 28 \\
\hline & & & & & & $\mathrm{Ca} / / \mathrm{K} 0 / \mathrm{Mg} 0 / \mathrm{P}-/ \mathrm{N}-$ & 26 \\
\hline & & & & & & $\mathrm{Ca} 0 / \mathrm{K}-/ \mathrm{Mg} 0 / \mathrm{P}-/ \mathrm{N} 0$ & 25 \\
\hline & & & & & & $\mathrm{Ca} 0 / \mathrm{K} 0 / \mathrm{Mg} 0 / \mathrm{P} 0 / \mathrm{N}-$ & 21 \\
\hline & & & & & & $\mathrm{Ca} 0 / \mathrm{K}-/ \mathrm{Mg} 0 / \mathrm{P}-/ \mathrm{N}-$ & 17 \\
\hline \multirow{13}{*}{ 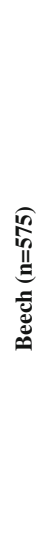 } & & & & & & $\mathrm{Ca} 0 / \mathrm{K} 0 / \mathrm{Mg} 0 / \mathrm{P}-/ \mathrm{N} 0$ & 104 \\
\hline & & & & & & $\mathrm{Ca} 0 / \mathrm{K} 0 / \mathrm{Mg} 0 / \mathrm{P} 0 / \mathrm{N} 0$ & 71 \\
\hline & & & & & & $\mathrm{Ca} 0 / \mathrm{K}-/ \mathrm{Mg} 0 / \mathrm{P}-/ \mathrm{N} 0$ & 53 \\
\hline & & & & & & $\mathrm{Ca} 0 / \mathrm{K} 0 / \mathrm{Mg} 0 / \mathrm{P} 0 / \mathrm{N}+$ & 51 \\
\hline & & & & & & $\mathrm{Ca} 0 / \mathrm{K} 0 / \mathrm{Mg}-/ \mathrm{P}-/ \mathrm{N} 0$ & 50 \\
\hline & & & & & & $\mathrm{Ca} 0 / \mathrm{K}-/ \mathrm{Mg} 0 / \mathrm{P} 0 / \mathrm{N} 0$ & 32 \\
\hline & & & & & & $\mathrm{Ca} / \mathrm{K} 0 / \mathrm{Mg} 0 / \mathrm{P}-/ \mathrm{N}-$ & 30 \\
\hline & & & & & & $\mathrm{Ca}-/ \mathrm{K} 0 / \mathrm{Mg}-/ \mathrm{P}-/ \mathrm{N} 0$ & 27 \\
\hline & & & & & & $\mathrm{Ca} 0 / \mathrm{K}-/ \mathrm{Mg} 0 / \mathrm{P} 0 / \mathrm{N}+$ & 24 \\
\hline & & & & & & $\mathrm{Ca} 0 / \mathrm{K}-/ \mathrm{Mg}-/ \mathrm{P}-/ \mathrm{NO}$ & 14 \\
\hline & & & & & & $\mathrm{Ca} 0 / \mathrm{K} 0 / \mathrm{Mg}-/ \mathrm{P} 0 / \mathrm{N} 0$ & 13 \\
\hline & & & & & & $\mathrm{Ca}-/ \mathrm{K} 0 / \mathrm{Mg}-/ \mathrm{P} 0 / \mathrm{N} 0$ & 12 \\
\hline & & & & & & $\mathrm{Ca} 0 / \mathrm{K}-/ \mathrm{Mg} 0 / \mathrm{P}-/ \mathrm{N}+$ & 12 \\
\hline \multirow{6}{*}{ 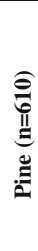 } & & & & & & $\mathrm{Ca} 0 / \mathrm{K} 0 / \mathrm{Mg} 0 / \mathrm{P} 0 / \mathrm{N}+$ & 198 \\
\hline & & & & & & $\mathrm{Ca} 0 / \mathrm{K} 0 / \mathrm{Mg} 0 / \mathrm{P} 0 / \mathrm{N} 0$ & 126 \\
\hline & & & & & & $\mathrm{Ca} 0 / \mathrm{K} 0 / \mathrm{Mg}-/ \mathrm{P} 0 / \mathrm{N}+$ & 57 \\
\hline & & & & & & $\mathrm{Ca} 0 / \mathrm{K} 0 / \mathrm{Mg}-/ \mathrm{P} 0 / \mathrm{N} 0$ & 32 \\
\hline & & & & & & $\mathrm{Ca} 0 / \mathrm{K}-/ \mathrm{Mg} 0 / \mathrm{P} 0 / \mathrm{N} 0$ & 25 \\
\hline & & & & & & $\mathrm{Ca} 0 / \mathrm{K} 0 / \mathrm{Mg} 0 / \mathrm{P}-/ \mathrm{N} 0$ & 23 \\
\hline \multirow{4}{*}{ 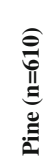 } & & & & & & $\mathrm{Ca} 0 / \mathrm{K} 0 / \mathrm{Mg} 0 / \mathrm{P}-/ \mathrm{N}+$ & 22 \\
\hline & & & & & & $\mathrm{Ca} / \mathrm{K} 0 / \mathrm{Mg}-/ \mathrm{P}-/ \mathrm{N}+$ & 18 \\
\hline & & & & & & $\mathrm{Ca}-/ \mathrm{K} 0 / \mathrm{Mg}-/ \mathrm{P} 0 / \mathrm{N} 0$ & 11 \\
\hline & & & & & & $\mathrm{Ca} 0 / \mathrm{K}-/ \mathrm{Mg} 0 / \mathrm{P}-/ \mathrm{N}+$ & 11 \\
\hline \multirow{6}{*}{$\begin{array}{c}\frac{\infty}{\infty} \\
\frac{11}{\sigma} \\
\frac{4}{0}\end{array}$} & & & & & & $\mathrm{Ca} 0 / \mathrm{K} 0 / \mathrm{Mg} 0 / \mathrm{P} 0 / \mathrm{N}+$ & 96 \\
\hline & & & & & & $\mathrm{Ca} 0 / \mathrm{K} 0 / \mathrm{Mg} 0 / \mathrm{P} 0 / \mathrm{N} 0$ & 61 \\
\hline & & & & & & $\mathrm{Ca} 0 / \mathrm{K} 0 / \mathrm{Mg} 0 / \mathrm{P}-/ \mathrm{N} 0$ & 42 \\
\hline & & & & & & $\mathrm{Ca} 0 / \mathrm{K} 0 / \mathrm{Mg} 0 / \mathrm{P}-/ \mathrm{N}+$ & 23 \\
\hline & & & & & & $\mathrm{Ca}-/ \mathrm{K} 0 / \mathrm{Mg} 0 / \mathrm{P} 0 / \mathrm{N}+$ & 11 \\
\hline & & & & & & $\mathrm{Ca} 0 / \mathrm{K} 0 / \mathrm{Mg}-/ \mathrm{P} 0 / \mathrm{N}+$ & 10 \\
\hline
\end{tabular}

The colours in the element columns and the symbols after the elements symbolize adequate supply (grey, 0), (latent) deficiency (white, -) and nitrogen surplus (black, N+) 
beech. For pine, $\mathrm{Mg}$ deficiency in combination with $\mathrm{N}$ surplus was frequently found $(\mathrm{Ca} 0 / \mathrm{K} 0 / \mathrm{Mg}-/ \mathrm{P} 0 / \mathrm{N}+)$, whereas for beech, $\mathrm{P}$ deficiency combined with $\mathrm{K}$ deficiency $(\mathrm{Ca} 0 / \mathrm{K}-/ \mathrm{Mg} 0 / \mathrm{P}-/ \mathrm{N} 0)$ and $\mathrm{Mg}$ deficiency $(\mathrm{Ca} 0 / \mathrm{K} 0 / \mathrm{Mg}-/ \mathrm{P}-/ \mathrm{N} 0)$, respectively, occurred frequently. Furthermore, surplus of $\mathrm{N}$ without concurrent deficiency of other nutrients $(\mathrm{Ca} 0 / \mathrm{K} 0 / \mathrm{Mg} 0 / \mathrm{P} 0 / \mathrm{N}+)$ was commonly observed for all tree species.

There do not appear to be any spatial patterns in the regional distribution of nutrition types. Using the spruce by way of example, the cartogram in Fig. 11.15 shows that a deficiency in $\mathrm{K}$ with otherwise balanced nutrient supply $(\mathrm{Ca} 0 / \mathrm{K}-/ \mathrm{Mg} 0 /$ $\mathrm{P} 0 / \mathrm{N} 0)$ or even in combination with a surplus of $\mathrm{N}(\mathrm{Ca} 0 / \mathrm{K}-/ \mathrm{Mg} 0 / \mathrm{P} 0 / \mathrm{N}+)$ occurred

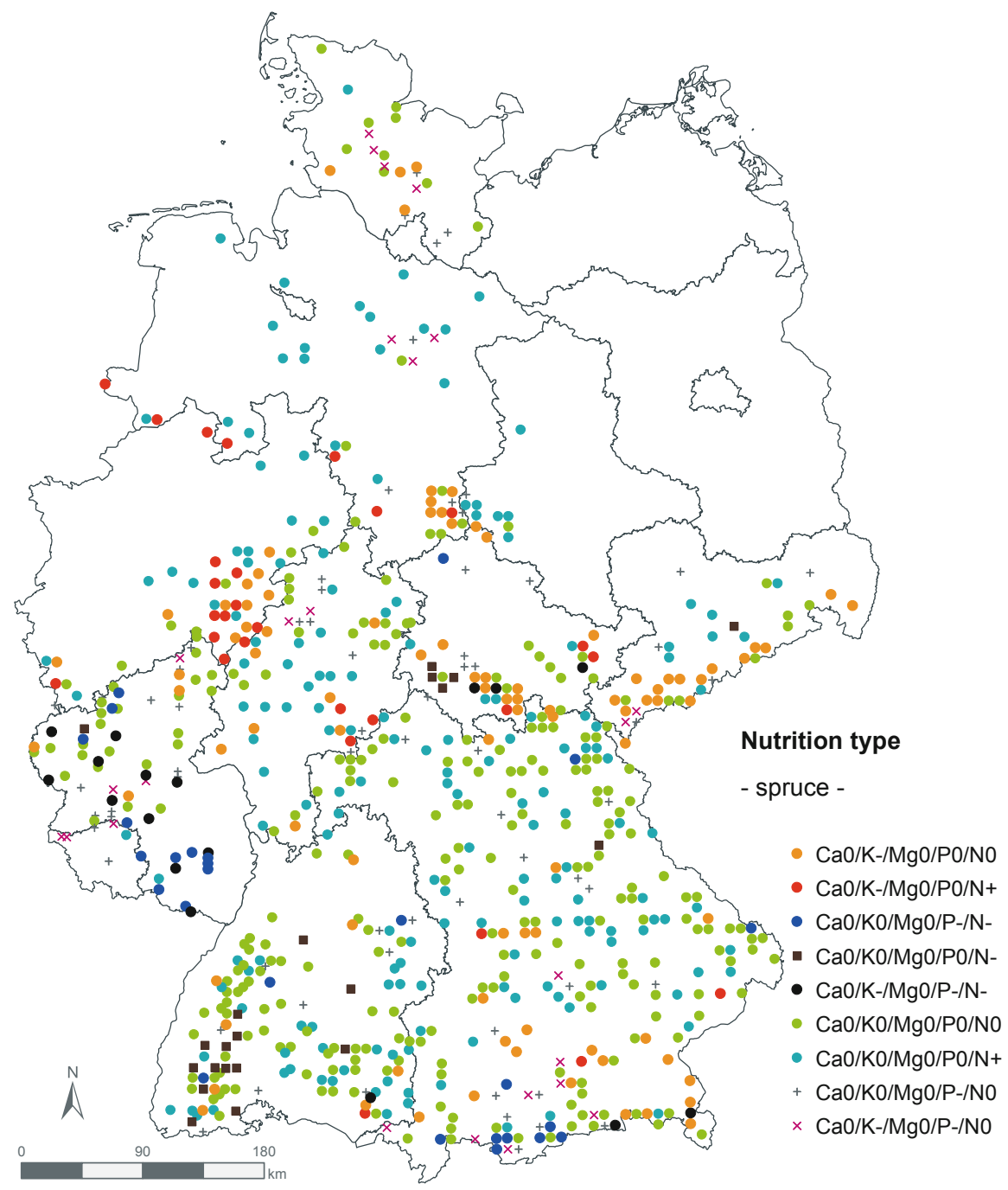

Fig. 11.15 Regional distribution of nutrition types using spruce as the example 
notably in the regions of the Erzgebirge, the Thuringian Forest, the Harz and the Sauerland and Siegerland. The parent material is most likely not the reason for the K deficiency in these regions. However, the spruce stands in these regions were limed several times, so that $\mathrm{K}$ deficiency is probably due to cation antagonism with Ca. Types with $\mathrm{N}$ deficiencies occurred regionally: in the Limestone Alps region in combination with a $\mathrm{P}$ deficiency $(\mathrm{Ca} 0 / \mathrm{K} 0 / \mathrm{Mg} 0 / \mathrm{P}-/ \mathrm{N}-)$, in Baden-Wuerttemberg (especially in the Black Forest) and in the northern regions of the Thuringian Forest with otherwise balanced nutrient supply $(\mathrm{Ca} 0 / \mathrm{K} 0 / \mathrm{Mg} 0 / \mathrm{P} 0 / \mathrm{N}-)$ and in the Rhineland-Palatinate area in combination with deficiencies of both $\mathrm{K}$ and $\mathrm{P}$ $(\mathrm{Ca} / \mathrm{K}-/ \mathrm{Mg} 0 / \mathrm{P}-/ \mathrm{N}-)$. All other nutrition types were distributed evenly throughout Germany with no particular regional hotspots.

We used discriminant analysis to investigate which site-specific and environmental factors were decisive for assignment to a specific nutrition type. In advance, the potential influencing parameters from the NFSI database were subjected to a principal component analysis. This procedure ensured that the linear correlations between the variables were eliminated. The number of variables to be extracted, or principal components, was determined based on the Kaiser criterion. A varimax rotation was used to simplify the interpretation of the results. Principal component values were calculated by regression using the statistical programme SPSS Statistics Release 22.0.0.0. Individual parameters for which the frequency distribution was not suitable for principal component analysis were log-transformed a priori.

Overall, 42 potential influencing factors were identified from the NFSI database and subjected to principal component analysis. These included parameters for soil chemistry, climate, modelled variables of soil water budget (see Chap. 3) and regionalized deposition data and critical load exceedances for nitrogen. Applying the Kaiser criterion, the principal component analysis extracted ten principal components that describe $79.2 \%$ of all the total variance for all parameters considered. The first five components alone accounted for more than half the variance. Assignment of individual variables to principal components was evident using the rotated component matrix.

Based on the component matrix, input variables were selected for the discriminant analysis. The following variables were chosen:

- Precipitation [mm year ${ }^{-1}$ ]

- Evapotranspiration $\left[\mathrm{mm}_{\mathrm{year}}{ }^{-1}\right]$

- Number of limings [-]

- Ntot deposition 1990-2007 [kg ha ${ }^{-1}$ year $\left.^{-1}\right]$

- K concentration (30-60 cm) [\% of cation exchange capacity]

- C stock (organic layer to $90 \mathrm{~cm}$ ) $\left[\mathrm{kg} \mathrm{ha}^{-1}\right]$

- $\mathrm{C} / \mathrm{P}$ ratio $(0-5 \mathrm{~cm})[-]$

- $\mathrm{pH}\left(\mathrm{H}_{2} \mathrm{O}\right)$ value in $30-60 \mathrm{~cm} \mathrm{[-]}$

- $\mathrm{C} / \mathrm{N}$ ratio (organic layer) $[-]$

- Available water capacity (root zone) [mm]

- Relative water storage (root zone) [\%]

- $\mathrm{N}$ stock (organic layer) $\left[\mathrm{kg} \mathrm{ha}^{-1}\right]$ 
With these variables, a total of 38 stepwise discriminant analyses were performed according to the number of nutrition types, and the percentage classification probabilities for each nutrition type were calculated using linear combination of the influencing parameters. For two nutrition types for beech $(\mathrm{Ca} 0 / \mathrm{K}-/ \mathrm{Mg}-/ \mathrm{P}-/ \mathrm{N} 0$ and $\mathrm{Ca} 0 / \mathrm{K} 0 / \mathrm{Mg}-/ \mathrm{P} 0 / \mathrm{N} 0)$ and one type for pine $(\mathrm{Ca} 0 / \mathrm{K} 0 / \mathrm{Mg}-/ \mathrm{P}-/ \mathrm{N}+)$, no significant discriminant function could be derived based on the variables listed. The results of the discriminant function analysis presented in Table 11.6 first indicate the numbers of each correctly classified site. In addition, for each variable, the table lists the correlation coefficient with the calculated percent classification probability for all sites for each tree species. Correlation coefficients for variables that were also included in the model based on stepwise discriminant function analysis are shown in bold.

Although the number of correctly classified sites was somewhat low at times, some variables showed strong and plausible correlations with the classification probabilities. For example, the probability of classifying nutrition types with surpluses of $\mathrm{N}$ is positively correlated with $\mathrm{N}$ deposition. However, in cases of both deficiency and normal levels of $\mathrm{N}$, there was a predominantly negative correlation. Considering $\mathrm{P}$ deficiency, there was often a strong correlation with the $\mathrm{C} / \mathrm{P}$ ratio at $0-5 \mathrm{~cm}$. This is the case especially for spruce $(\mathrm{Ca} 0 / \mathrm{K} 0 / \mathrm{Mg} 0 / \mathrm{P}-/ \mathrm{N} 0$ and $\mathrm{Ca} 0 / \mathrm{K}-/$ $\mathrm{Mg} 0 / \mathrm{P}-/ \mathrm{N} 0$ types $)$ and pine $(\mathrm{Ca} 0 / \mathrm{K} 0 / \mathrm{Mg} 0 / \mathrm{P}-/ \mathrm{N}+)$.

One notable result was the relationship of deficiency in $\mathrm{K}$ (sometimes in combination with a surplus of $\mathrm{N}$ and a deficiency of $\mathrm{P}$ ) and the number of limings. This result was consistent with the findings of Chap. 9. For example, this relationship could be seen in scatter plots for the spruce nutrition types $\mathrm{Ca} 0 / \mathrm{K}-/ \mathrm{Mg} 0 / \mathrm{P} 0 / \mathrm{N} 0$ (Fig. 11.16) and $\mathrm{Ca} 0 / \mathrm{K}-/ \mathrm{Mg} 0 / \mathrm{P} 0 / \mathrm{N}+$ (Fig. 11.17). For the $\mathrm{K}$ deficiency type with no $\mathrm{N}$ surplus, there was a relatively strong correlation of classification probability with the plant available $\mathrm{K}$ in the soil. In addition, there was a high classification probability with narrow $\mathrm{C} / \mathrm{N}$ ratios, which suggested possible competition between $\mathrm{K}$ and both $\mathrm{NH}_{4}^{+}$and $\mathrm{Ca}$ on alkaline-rich sites. There was also a positive correlation with $\mathrm{N}$ deposition. The classification probability increased considerably with the number of limings; this result might be explained by $\mathrm{Ca}-\mathrm{K}$ antagonism. In examining the probability of classification to the $\mathrm{N}$ surplus nutrition-type $\mathrm{Ca} 0 / \mathrm{K}-/ \mathrm{Mg} 0 / \mathrm{P} 0 / \mathrm{N}+$, it is clear that there was no longer a relationship to available $\mathrm{K}$ in the soil; instead, in this case, the $\mathrm{N}$ deposition appeared to induce the $\mathrm{K}$ deficiency. For this nutrition type as well, an increased number of limings was associated with a higher classification probability. Moreover, the probability of a $\mathrm{K}$ deficiency is higher with lower quantities of soil water available to plants.

Thus, overall the results indicated that the supply of $\mathrm{K}$ in the soil (as applicable, in combination with liming events) is extremely important for the $\mathrm{Ca} 0 / \mathrm{K}-/ \mathrm{Mg} 0 / \mathrm{P} 0 / \mathrm{N} 0$ nutrition type, while the $\mathrm{N}$ deposition is more likely responsible for the $\mathrm{K}$ deficiency in the $\mathrm{Ca} 0 / \mathrm{K}-/ \mathrm{Mg} 0 / \mathrm{P} 0 / \mathrm{N}+$ nutrition type.

The following logistical relationship can be calculated for the relation between classification probability and $\mathrm{N}$ deposition illustrated in Fig. 11.16: 


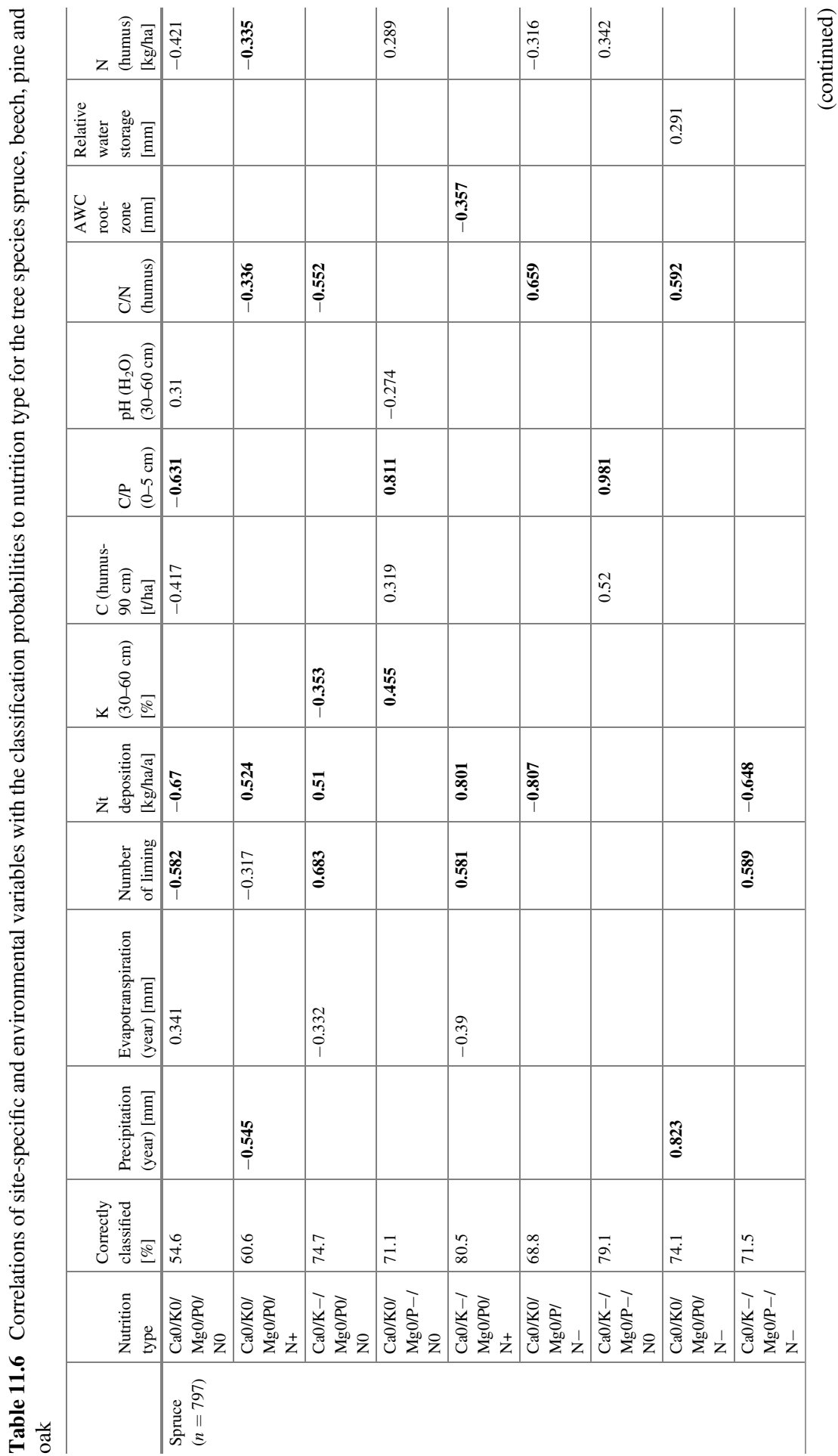




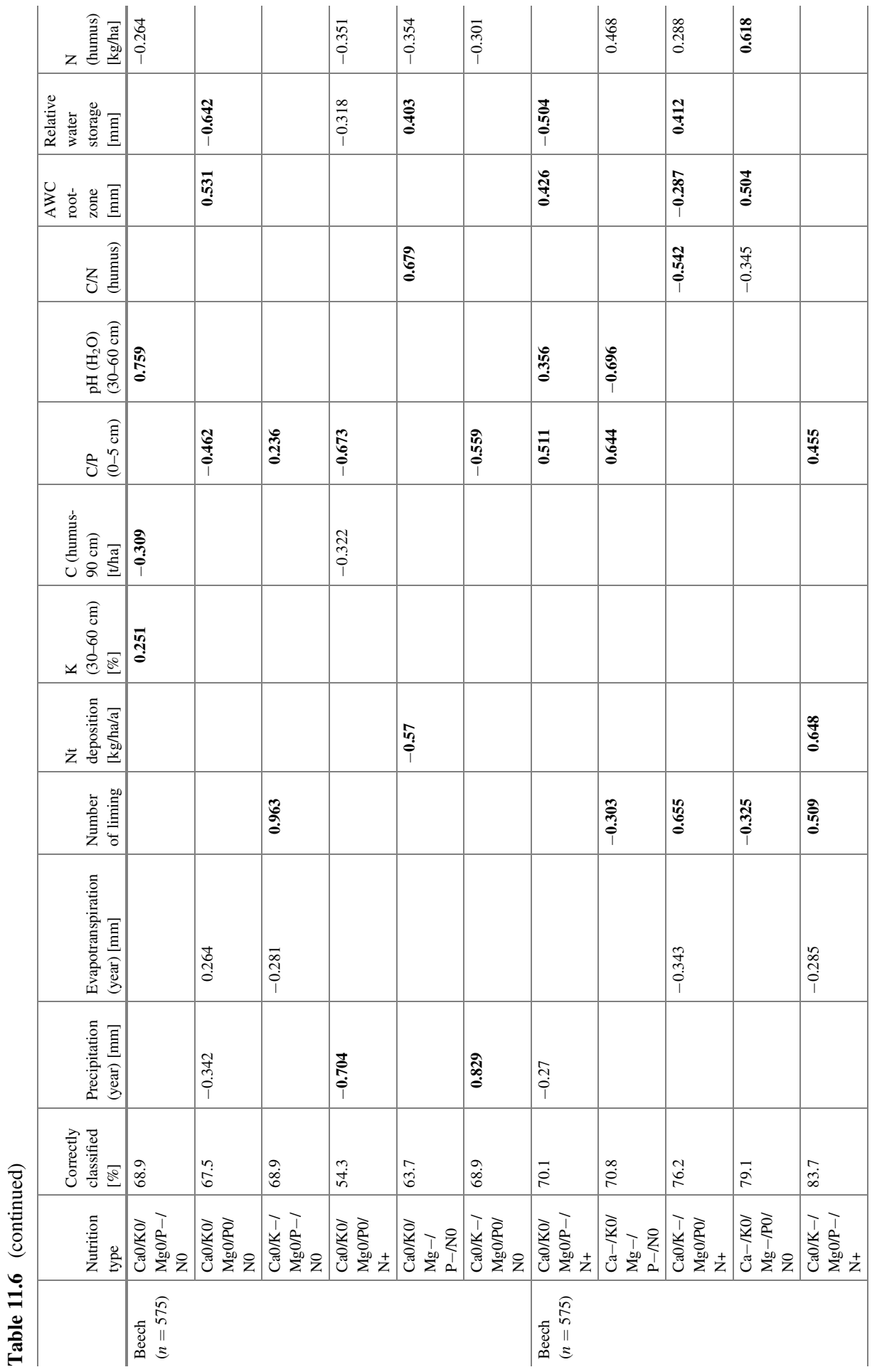




\begin{tabular}{|c|c|c|c|c|c|c|c|c|c|c|c|}
\hline 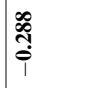 & & & & & & $\frac{\stackrel{c}{m}}{3}$ & & & $\begin{array}{c}n \\
\tilde{m} \\
i \\
i\end{array}$ & & \\
\hline & \begin{tabular}{l}
$\infty$ \\
\multirow{1}{*}{} \\
$\substack{1 \\
1}$
\end{tabular} & & & 商 & & & 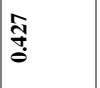 & & & 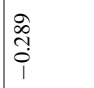 & \\
\hline & & & & & ले & & & & & & \\
\hline 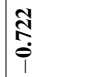 & $\stackrel{t}{\stackrel{s}{s}}$ & 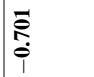 & 常 & 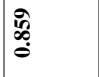 & 商 & & & & & & \\
\hline & & & & & 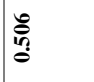 & ลั & & & 昂 & $\begin{array}{c}\infty \\
\infty \\
\tilde{i} \\
i\end{array}$ & \\
\hline & & $\stackrel{5}{\stackrel{5}{0}}$ & & & & 党 & & 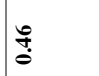 & & 胥 & \\
\hline & & & 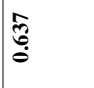 & & & & & 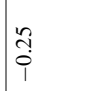 & & & \\
\hline 厄્. & $\begin{array}{l}\hat{\hat{A}} \\
\hat{i}\end{array}$ & & & $\begin{array}{l}\hat{A} \\
\hat{A} \\
i \\
i\end{array}$ & 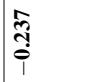 & & & & 趈 & $\begin{array}{l}\stackrel{1}{0} \\
\stackrel{0}{0} \\
\stackrel{i}{i}\end{array}$ & 苞 \\
\hline & & & $\stackrel{2}{\stackrel{9}{8}}$ & & 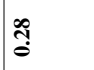 & & & & & & 胥 \\
\hline & & & & $\overline{\tilde{o}}$ & สึ่ & & & & & & \\
\hline & $\frac{o}{m}$ & : & & $\begin{array}{l}\overline{1} \\
\tilde{\omega} \\
\hat{0}\end{array}$ & $\stackrel{f}{\stackrel{f}{S}}$ & & & & 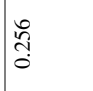 & & \\
\hline ㅇ. & $\underset{\text { in. }}{\stackrel{\text { in }}{ }}$ & $\begin{array}{l}+ \\
\dot{B}\end{array}$ & $\underset{g}{\stackrel{d}{0}}$ & 亲 & $\underset{\substack{+\propto}}{\stackrel{\infty}{\infty}}$ & $\frac{n}{2}$ & $\stackrel{0}{\circ}$ & $\stackrel{n}{\infty}$ & $\overrightarrow{8}$ & ì. & 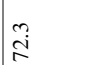 \\
\hline 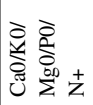 & 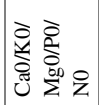 & 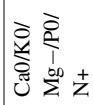 & 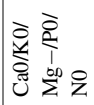 & 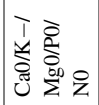 & 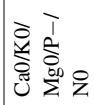 & 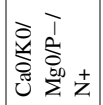 & 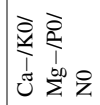 & 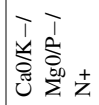 & 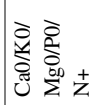 & 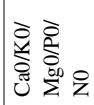 & 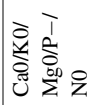 \\
\hline 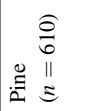 & & & & & & & & & 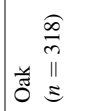 & & \\
\hline
\end{tabular}




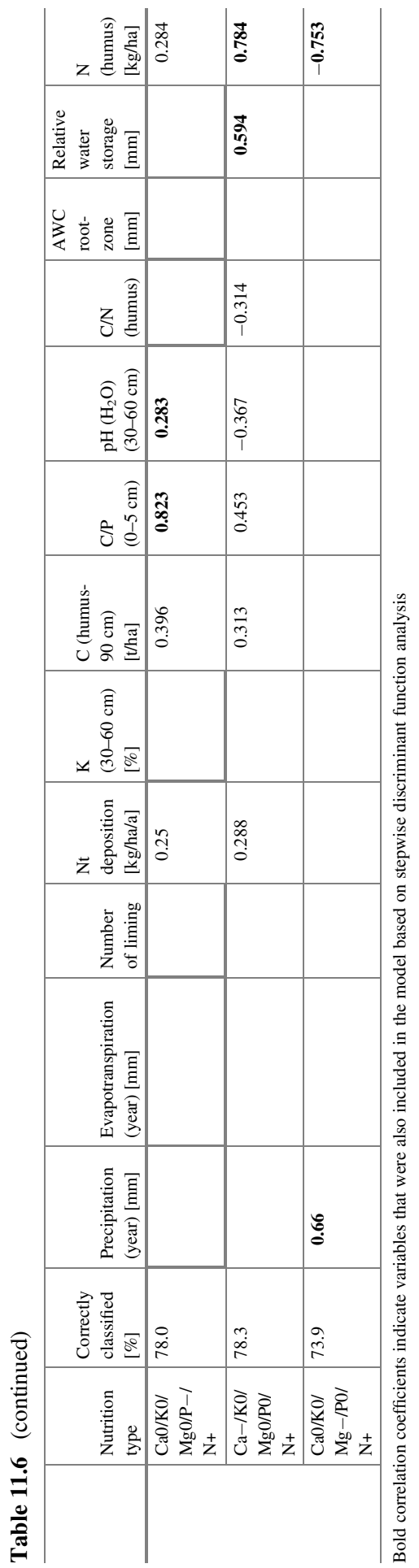



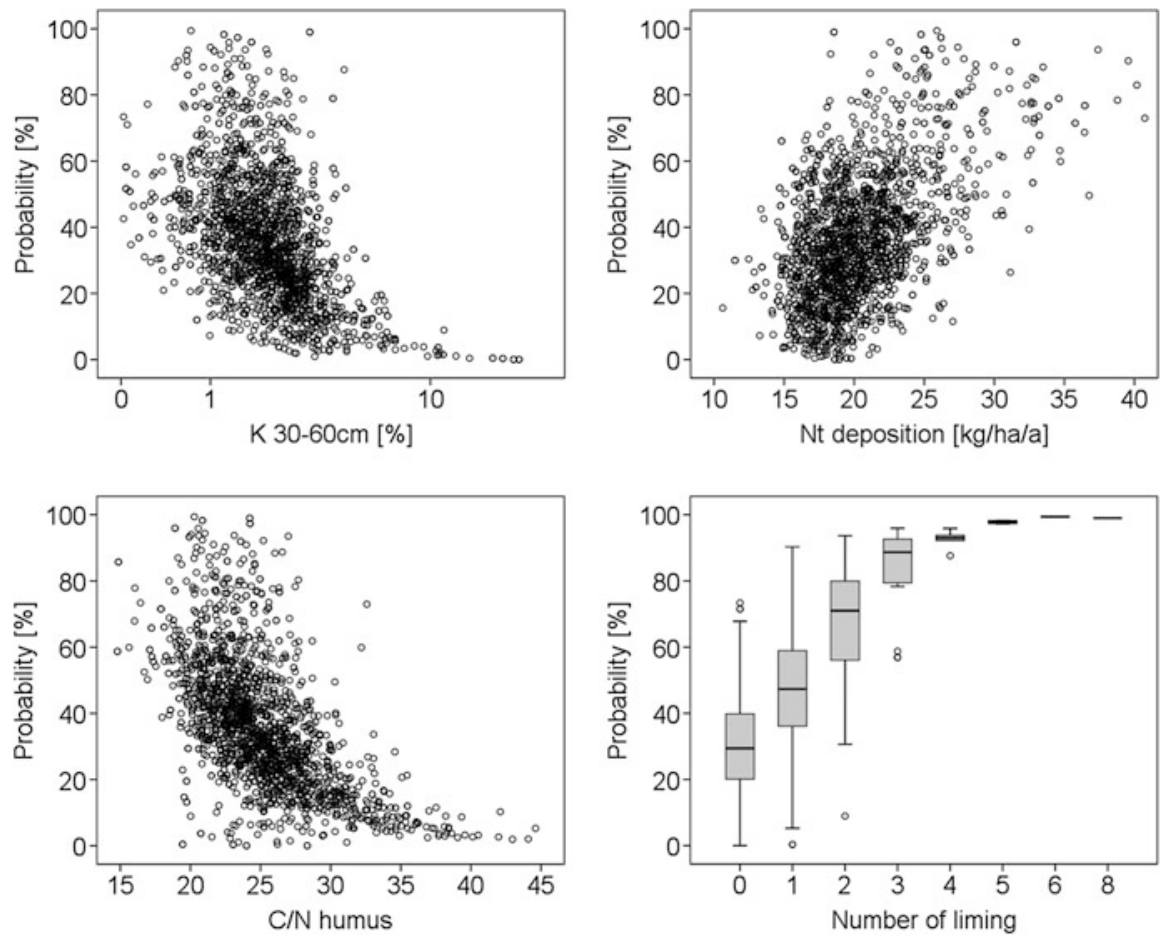

Fig. 11.16 Relationships between the classification probability to spruce nutrition-type $\mathrm{Ca} 0 / \mathrm{K}-/$ $\mathrm{Mg} 0 / \mathrm{P} 0 / \mathrm{N} 0$ and exchangeable $\mathrm{K}$ at a depth of $30-60 \mathrm{~cm}, \mathrm{~N}$ deposition, $\mathrm{C} / \mathrm{N}$ ratio in the organic layer and the number of liming events

$$
\text { Probability }=1 /\left(1+3184.64^{*} 0.7212 \mathrm{Nt}\right) ; \quad R^{2}=0.71
$$

This equation shows that a $\mathrm{K}$ deficiency was increasingly likely (probability $>50 \%$ ) with $\mathrm{N}$ input when input rates are greater than $24.7 \mathrm{~kg} \mathrm{ha}^{-1}$ year $^{-1}$ and at input rates above $33.7 \mathrm{~kg} \mathrm{ha}^{-1}$ year $^{-1}$, there was an exceptionally high risk of $\mathrm{K}$ deficiency (probability $>95 \%$ ). Under these conditions, the growth stimulated by the addition of $\mathrm{N}$ means that nutrients and water must be taken up at greater quantities and antagonism between $\mathrm{NH}_{4}^{+}$and other cationic nutrients becomes increasingly important. Beyond the thresholds, the demand for $\mathrm{K}$ can apparently no longer be met and a $\mathrm{K}$ deficiency arises, largely independent of the $\mathrm{K}$ supply at the site. 

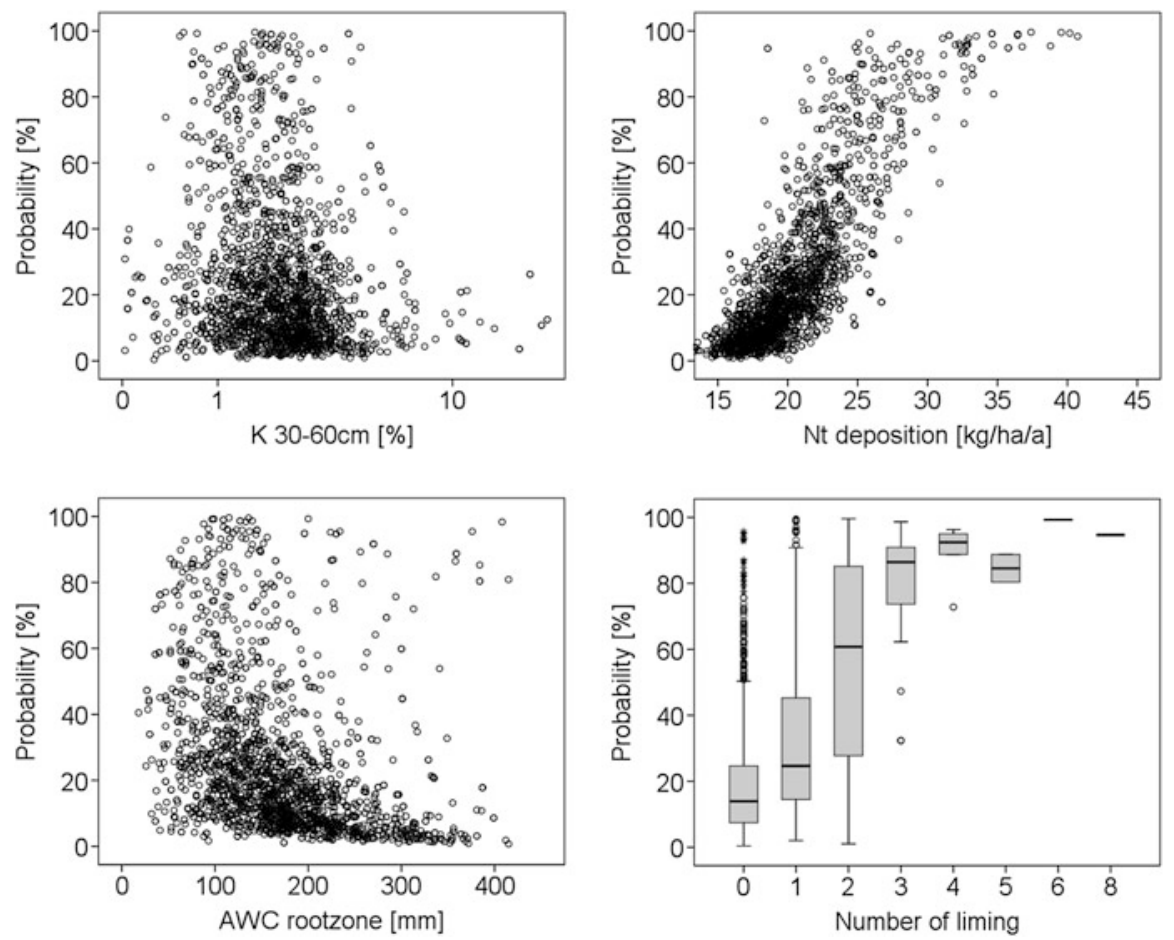

Fig. 11.17 Relationships between the classification probability to spruce nutrition-type $\mathrm{Ca} / \mathrm{K}-/$ $\mathrm{Mg} 0 / \mathrm{P} 0 / \mathrm{N}+$ and exchangeable $\mathrm{K}$ at a depth of $30-60 \mathrm{~cm}, \mathrm{~N}$ deposition, water capacity in the root zone available to plants and the number of liming events

\subsection{Combined Defoliation Development Types and Nutrition Types}

Defoliation development types and nutrition types were cross-tabled. There were few clear spatial patterns in the regional distribution of combined defoliation development types and nutrition types, which is most likely due to different factors that were decisive for assignment to a specific defoliation development type (see Sect. 11.3) and nutrition type (see Sect. 11.4), respectively. For spruce, however, various nutrient deficiencies $(\mathrm{P}, \mathrm{K}, \mathrm{N})$ could be observed for defoliation development type 3 in particular (Table 11.7), which also was characterized by comparably high defoliation in the last decade. Defoliation development type 4 had the highest defoliation in recent years, and $\mathrm{N}$ deficiency was predominantly found for this type. Defoliation of beech showed a strong negative association to N nutrition (see Sect. 11.3.2). Defoliation development types 2 and 5 of beech frequently belonged to the $\mathrm{N}$ surplus nutrition type and their defoliation time series showed no trends, which was in 
11 Spatial Response Patterns in Biotic Reactions of Forest Trees and...

Table 11.7 Example of a cross table of defoliation development and nutrition types for spruce

\begin{tabular}{|c|c|c|c|c|c|c|c|}
\hline \multirow[b]{2}{*}{ Nutrition type } & & \multicolumn{6}{|c|}{ Defoliation development type of spruce } \\
\hline & & 1 & 2 & 3 & 4 & 5 & Row $_{\text {tot }}$ \\
\hline \multirow{3}{*}{$\begin{array}{l}\mathrm{Ca} 0 / \mathrm{K}-/ \mathrm{Mg} 0 / \\
\mathrm{P}-/ \mathrm{N}-\end{array}$} & Count & 0 & 2 & 11 & 1 & 3 & 17 \\
\hline & Expected count & 0.55 & 3.90 & 3.79 & 3.63 & 5.14 & \\
\hline & Std. residuals & -0.74 & -0.96 & 3.70 & -1.38 & -0.94 & \\
\hline \multirow{3}{*}{$\begin{array}{l}\mathrm{Ca} 0 / \mathrm{K}-/ \mathrm{Mg} 0 / \\
\mathrm{P}-/ \mathrm{N} 0\end{array}$} & Count & 3 & 5 & 5 & 2 & 7 & 22 \\
\hline & Expected count & 0.71 & 5.05 & 4.91 & 4.69 & 6.65 & \\
\hline & Std. residuals & 2.72 & -0.02 & 0.04 & -1.24 & 0.14 & \\
\hline \multirow{3}{*}{$\begin{array}{l}\mathrm{Ca} 0 / \mathrm{K}-/ \mathrm{Mg} 0 / \\
\mathrm{P} 0 / \mathrm{N}+\end{array}$} & Count & 0 & 8 & 12 & 1 & 4 & 25 \\
\hline & Expected count & 0.81 & 5.74 & 5.57 & 5.33 & 7.55 & \\
\hline & Std. residuals & -0.90 & 0.95 & 2.72 & -1.88 & -1.29 & \\
\hline \multirow{3}{*}{$\begin{array}{l}\mathrm{Ca} 0 / \mathrm{K}-/ \mathrm{Mg} 0 / \\
\mathrm{P} 0 / \mathrm{N} 0\end{array}$} & Count & 3 & 21 & 17 & 8 & 29 & 78 \\
\hline & Expected count & 2.52 & 17.90 & 17.39 & 16.63 & 23.56 & \\
\hline & Std. residuals & 0.30 & 0.73 & -0.09 & -2.12 & 1.12 & \\
\hline \multirow{3}{*}{$\begin{array}{l}\mathrm{Ca} 0 / \mathrm{K} 0 / \mathrm{Mg} 0 / \\
\mathrm{P}-/ \mathrm{N}-\end{array}$} & Count & 0 & 0 & 8 & 7 & 3 & 18 \\
\hline & Expected count & 0.58 & 4.13 & 4.01 & 3.84 & 5.44 & \\
\hline & Std. residuals & -0.76 & -2.03 & 2.00 & 1.61 & -1.05 & \\
\hline \multirow{3}{*}{$\begin{array}{l}\mathrm{Ca} 0 / \mathrm{K} 0 / \mathrm{Mg} 0 / \\
\mathrm{P}-/ \mathrm{N} 0\end{array}$} & Count & 3 & 15 & 16 & 10 & 17 & 61 \\
\hline & Expected count & 1.97 & 13.99 & 13.60 & 13.01 & 18.43 & \\
\hline & Std. residuals & 0.73 & 0.27 & 0.65 & -0.83 & -0.33 & \\
\hline \multirow{3}{*}{$\begin{array}{l}\mathrm{Ca} 0 / \mathrm{K} 0 / \mathrm{Mg} 0 / \\
\mathrm{P} 0 / \mathrm{N}-\end{array}$} & Count & 0 & 3 & 1 & 11 & 2 & 17 \\
\hline & Expected count & 0.55 & 3.90 & 3.80 & 3.63 & 5.14 & \\
\hline & Std. residuals & -0.74 & -0.46 & -1.43 & 3.87 & -1.38 & \\
\hline \multirow{3}{*}{$\begin{array}{l}\mathrm{Ca} 0 / \mathrm{K} 0 / \mathrm{Mg} 0 / \\
\mathrm{P} 0 / \mathrm{N}+\end{array}$} & Count & 3 & 42 & 26 & 30 & 44 & 145 \\
\hline & Expected count & 4.69 & 33.26 & 32.33 & 30.92 & 43.81 & \\
\hline & Std. residuals & -0.78 & 1.52 & -1.11 & -0.17 & 0.03 & \\
\hline \multirow{3}{*}{$\begin{array}{l}\mathrm{Ca} 0 / \mathrm{K} 0 / \mathrm{Mg} 0 / \\
\mathrm{P} 0 / \mathrm{N} 0\end{array}$} & Count & 6 & 40 & 39 & 55 & 73 & 213 \\
\hline & Expected count & 6.88 & 48.86 & 47.49 & 45.42 & 64.35 & \\
\hline & Std. residuals & -0.34 & -1.27 & -1.23 & 1.42 & 1.08 & \\
\hline $\mathrm{Col}_{\text {tot }}$ & & 20 & 142 & 138 & 132 & 187 & 619 \\
\hline
\end{tabular}

Observed count, the expected count from the chi-square test and the standardized residuals are presented

contrast to the other types. Defoliation development type 1 was the only type where adequate nutrient supply was primarily observed and defoliation was lowest in recent years. Hence, nutrient deficiencies may enhance the sensitivity of trees to drought stress. 


\subsection{Conclusion}

This chapter focused on spatial patterns in the biotic reactions of forest trees and their association with conditions and changes in forest soils and other environmental variables. Secondary tree growth, tree defoliation and tree nutrition, primarily of the four main tree species of Germany, were considered as biotic reactions indicating tree vitality. Associations of growth ring widths and defoliation with indices of drought stress were found. Growth ring widths, in particular of spruce and beech, decreased with low soil water availability and with pronounced dry periods. In addition, at higher temperature ranges, a decline or plateau of the annual growth ring widths was evident. High annual mean temperature deviations of approximately $1.5^{\circ} \mathrm{C}$ and more from the long-term mean (1961-1990) and particularly when accompanied by high negative precipitation deviations were also associated with increased defoliation of all tree species. Defoliation development types that showed clear large-scale spatial distribution patterns were identified. The defoliation development types were in good accordance with the landscape regions of Germany. Weather conditions and in particular relative deviations of temperature and precipitation from the long-term mean explained a large proportion of differences among defoliation development types. The defoliation development types found in the south-western part of Germany (especially the area of Baden-Wuerttemberg but also adjacent areas in southern Hesse and areas of Rhineland-Palatinate and Saarland) have been characterized by the highest defoliation of all species in the last years of observation, most likely due foremost to the strongest and frequent positive deviations of temperature with negative deviations of precipitation beginning in 2003. Hence, south-western Germany is an area with high risk for high defoliation, at least in recent years. Large parts of this area also had a low mass of organic layer, which might protect the soil against drying up. Although there were few clear spatial patterns in the regional distribution of nutrition types as well as of combined defoliation development types and nutrition types, different nutrition deficiencies (K, P, N) were cumulatively observed in parts of south-western Germany. Nutrient deficiencies may enhance the sensitivity of trees to drought stress. The results of the investigation of nutrition types revealed that nutrition of trees generally was adequate or characterized by $\mathrm{N}$ surplus with the exception of beech, where $\mathrm{P}$ deficiency was most common. The situation of $\mathrm{N}$ nutrition was mainly associated with $\mathrm{N}$ deposition. In regions with high $\mathrm{N}$ deposition, deficiency of $\mathrm{K}$ was also related to $\mathrm{N}$ deposition, presumably because of antagonistic effects between $\mathrm{K}$ and $\mathrm{NH}_{4}^{+}$. However, in regions with low or normal $\mathrm{N}$ deposition, $\mathrm{K}$ deficiency was mainly a result of low $\mathrm{K}$ stocks in the soil. Independent of $\mathrm{N}$ deposition, liming was also associated with $\mathrm{K}$ deficiency, again presumably because of antagonistic effects (Ca-K antagonism), which also appeared to play a role in tree defoliation, especially in pine.

In considering the results of the NFSI II presented in the previous chapters of this book, changes in weather conditions and in particular in available soil water 
(see Chap. 3) certainly had the strongest impact on biotic tree reactions. Changes in $\mathrm{C}$ and total stocks in the organic layer (see Chap. 6) were also important in this context, since the organic layer most likely reduces drying up and thus drought stress. Hence, drought stress was the main risk factor detected. In central Europe, a further increase in the frequency of summer drought (high temperature combined with low precipitation) is expected as consequence of climate change (Lindner et al. 2010). Environmental policy should primarily aim at mitigating climate change. Additionally, silviculture measures are crucial: for example, consideration should be given to increased diversity of tree species adapted to the site conditions. Positive and negative aspects of liming in terms of nutrition supply need to be evaluated on a plot-by-plot basis. Liming might cause further drying of soils, because it alters the decomposition and distribution of organic matter in the organic layer and soil; these effects should be considered and discussed. Attention should also be paid to the effect of chronic high $\mathrm{N}$ depositions and possible interactions with the effects of climate change. Measures should aim to reduce stress factors originating from air pollution and nutrient deficiencies in order to facilitate the regenerative capability of forest trees and adaption to climate change.

Acknowledgments We would like to thank the Northwest German Forest Research Institute for providing their drill core data. We further thank the responsible institutions of the federal states for providing the data of the Forest Condition Survey of their denser grids. In addition, we acknowledge the discussion with Inge Dammann (Northwest German Forest Research Institute).

\section{References}

Aber JD, McDowell W, Nadelhoffer K, Magill A, Berntson G, Kamakea M, McNulty S, Currie W, Rustad L, Fernandez I (1998) Nitrogen saturation in temperate forest ecosystems-hypotheses revisited. Bioscience 48(11):921-934. https://doi.org/10.2307/1313296

Alavi G (2002) The impact of soil moisture on stem growth of spruce forest during a 22-year period. For Ecol Manag 166(1-3):17-33

Anders S, Beck W, Lux W, Müller J, Fischer R, König A, Küppers JG, Thoroe C, Kätzel R, Löffler S, Heydeck P, Möller K (2004) Auswirkung der Trockenheit 2003 auf Waldzustand und Waldbau. Interim Report, vol BMVEL 533-7120/1. Federal Research Institute for Forest and Timber Industries, Eberswalde

Augustin NH, Musio M, von Wilpert K, Kublin E, Wood SN, Schumacher M (2009) Modeling spatiotemporal forest health monitoring data. J Am Stat Assoc 104(487):899-911. https://doi. org/10.1198/jasa.2009.ap07058

Berge E, Bartnicki J, Olendrzynski K, Tsyro SG (1999) Long-term trends in emissions and transboundary transport of acidifying air pollution in Europe. J Environ Manag 57(1):31-50. https://doi.org/10.1006/jema.1999.0275

Bolte A, Czajkowski T, Cocozza C, Tognetti R, de Miguel M, Pšidová E, Ditmarova L, Dinca L, Delzon S, Cochard H, Ræbild A, de Luis M, Cvjetkovic B, Heiri C, Müller J (2016) Desiccation and mortality dynamics in seedlings of different European beech (Fagus sylvatica 1.) populations under extreme drought conditions. Front Plant Sci 7:1-12. https://doi.org/10.3389/fpls.2016. 00751 
de Marco A, Proietti C, Cionni I, Fischer R, Screpanti A, Vitale M (2014) Future impacts of nitrogen deposition and climate change scenarios on forest crown defoliation. Environ Pollut 194:171-180. https://doi.org/10.1016/j.envpol.2014.07.027

de Vries W, Dobbertin MH, Solberg S, Van Dobben HF, Schaub M (2014) Impacts of acid deposition, ozone exposure and weather conditions on forest ecosystems in Europe: an overview. Plant Soil 380(1-2):1-45

Eichhorn J, Icke R, Isenberg A, Paar U, Schönfelder E (2005) Temporal development of crown condition of beech and oak as a response variable for integrated evaluations. Eur J For Res 124 (4):335-347. https://doi.org/10.1007/s10342-005-0097-z

Eichhorn J, Roskams P, Potočić N, Timmermann V, Ferretti M, Mues V, Szepesi A, Durrant D, Seletković I, Schroeck H-W, Nevalainen S, Bussotti F, Paloma G, Wulff S (2016) Part IV Visual assessment of crown condition and damaging agents. In: UNECE ICP Forests Programme Co-ordinating Centre (ed) Manual on methods and criteria for harmonized sampling, assessment, monitoring and analysis of the effects of air pollution on forests. Thünen Institute of Forest Ecosystems, Eberswalde, 54 pp

Eickenscheidt N, Augustin NH, Wellbrock N, Dühnelt P-E, Hilbrig L (2016) Kronenzustand Steuergrößen und Raum-Zeit-Entwicklung von 1989-2015. In: Wellbrock N, Bolte A, Flessa H (eds) Dynamik und räumliche Muster forstlicher Standorte in Deutschland - Ergebnisse der Bodenzustandserhebung im Wald 2006 bis 2008. Thünen Report 43. Johann Heinrich von Thünen Institute, Federal Research Institute for Rural Areas, Forestry and Fisheries, Braunschweig, pp 387-456

Eickenscheidt N, Augustin NH, Wellbrock N (2019) Spatio-temporal trend estimation of tree defoliation in Germany from 1989 to 2015 and grid examination using generalized additive mixed models. iForest-Biogeosciences and Forestry. Accepted for publication

Elith J, Leathwick JR, Hastie T (2008) A working guide to boosted regression trees. J Anim Ecol 77 (4):802-813. https://doi.org/10.1111/j.1365-2656.2008.01390.x

Ellenberg H (1996) Vegetation Mitteleuropas mit den Alpen in ökologischer Sicht. Ulmer, Stuttgart

Evers FH, Hüttl RF (1992) Magnesium-, Calcium-und Kaliummangel bei Waldbäumen Ursachen, Symptome, Behebung. Merkblätter der Forstlichen Versuchs- und Forschungsanstalt Baden-Württemberg, vol 42. Forest Research Institute Baden-Württemberg, Kassel

Ferretti M, Nicolas M, Bacaro G, Brunialti G, Calderisi M, Croisé L, Frati L, Lanier M, Maccherini S, Santi E, Ulrich E (2014) Plot-scale modelling to detect size, extent, and correlates of changes in tree defoliation in French high forests. For Ecol Manag 311:56-69. https://doi.org/ 10.1016/j.foreco.2013.05.009

Fraley C, Raftery AE, Scrucca L, Murphy TB, Fop M (2017) Mclust: Gaussian mixture modelling for model-based clustering, classification, and density estimation, R package Version 5.3. https://cran.rproject.org/web/packages/mclust/index.html

Galloway JN, Townsend AR, Erisman JW, Bekunda M, Cai ZC, Freney JR, Martinelli LA, Seitzinger SP, Sutton MA (2008) Transformation of the nitrogen cycle: recent trends, questions, and potential solutions. Science 320(5878):889-892. https://doi.org/10.1126/science.1136674

Göttlein A (2015) Grenzwertbereiche für die ernährungsdiagnostische Einwertung der Hauptbaumarten Fichte, Kiefer, Eiche, Buche. Allg Forst Jagdztg 186(5/6):110-116

Klap JM, Voshaar JHO, De Vries W, Erisman JW (2000) Effects of environmental stress on forest crown condition in Europe. Part IV: statistical analysis of relationships. Water Air Soil Pollut 119(1-4):387-420. https://doi.org/10.1023/a:1005157208701

Lin XH, Zhang DW (1999) Inference in generalized additive mixed models by using smoothing splines. J R Stat Soc Ser B Stat Methodol 61:381-400. https://doi.org/10.1111/1467-9868. 00183

Lindner M, Maroschek M, Netherer S, Kremer A, Barbati A, Garcia-Gonzalo J, Seidl R, Delzon S, Corona P, Kolstrom M, Lexer MJ, Marchetti M (2010) Climate change impacts, adaptive capacity, and vulnerability of European forest ecosystems. For Ecol Manag 259(4):698-709. https://doi.org/10.1016/j.foreco.2009.09.023 
Pinheiro JC, Bates DM (2000) Mixed-effects models in S and S-PLUS Springer. Springer, New York

R Core Team (2017) R: A language and environment for statistical computing. R Foundation for Statistical Computing, Vienna, Austria

Riek W, Wolff B (1999) Integrierende Auswertung bundesweiter Waldzustandsdaten. Final Report on the project "Integrierende Auswertung bundesweiter Waldschadens-, Bodenzustands-, Klima- und Immissionsdaten mittels multivariat-statistischer Modellbildung zur Interpretation neuartiger Waldschäden und Ableitung von Maßnahmenempfehlungen”. Federal Research Institute for Forestry and Timber Industries, Eberswalde

Scharnweber T, Manthey M, Criegee C, Bauwe A, Schröder C, Wilmking M (2011) Drought matters-declining precipitation influences growth of Fagus sylvatica L. and Quercus robur L. in north-eastern Germany. For Ecol Manag 262(6):947-961

Schwarz G (1978) Estimating the dimension of a model. Ann Stat 6(2):461-464

Seidling W (2001) Integrative studies on forest ecosystem conditions: multivariate evaluation on tree crown condition for two areas with distinct deposition gradients. Work report of the Institute for World Forestry. Federal Research Centre for Forestry and Forest Products, Hamburg

Seidling W (2004) Crown condition within integrated evaluations of Level II monitoring data at the German level. Eur J For Res 123(1):63-74

Seidling W (2006) Auswirkungen von klimatischem Trockenstress auf den Waldzustand. Arbeitsbericht (Working Report). Federal Research Institute for Forest and Timber Industries (Centre for Forest Ecology and Inventory) \& Eberswalde University for Applied Sciences, Eberswalde

Seidling W (2007) Signals of summer drought in crown condition data from the German Level I network. Eur J For Res 126(4):529-544. https://doi.org/10.1007/s10342-007-0174-6

Seidling W, Mues V (2005) Statistical and geostatistical modelling of preliminarily adjusted defoliation on an European scale. Environ Monit Assess 101(1-3):223-247

Seidling W, Ziche D, Beck W (2012) Climate responses and interrelations of stem increment and crown transparency in Norway spruce, Scots pine, and common beech. For Ecol Manag 284:196-204. https://doi.org/10.1016/j.foreco.2012.07.015

Silverman BW (1985) Some aspects of the spline smoothing approach to non-parametric regression curve fitting. J R Stat Soc Ser B Methodol 47(1):1-52

Solberg S (2004) Summer drought: a driver for crown condition and mortality of Norway spruce in Norway. For Pathol 34(2):93-104. https://doi.org/10.1111/j.1439-0329.2004.00351.x

Thormann B (2014) Zuwachsverhalten von Buche und Fichte im Hinblick auf die Trockenjahre 1976 und 2003: Eine Analyse von dendrochronologischen Zuwachsdaten der Bodenzustandserhebung in Nord-West Deutschland. Master theses. Georg August University, Göttingen

van der Loo M, van der Laan J, R Core Team, Logan N (2017) stringdist: approximate string matching and string distance functions, R Package Version 0.9.6.4. https://cran.r-project.org/ web/packages/stringdist/index.html

Wahba G (1983) Bayesian "confidence intervals" for the cross-validated smoothing spline. J R Stat Soc Ser B Methodol 45(1):133-150

Wellbrock N, Bolte A, Flessa H (eds) (2016) Dynamik und räumliche Muster forstlicher Standorte in Deutschland: Ergebnisse der Bodenzustandserhebung im Wald 2006 bis 2008. Thünen Report 43. Johann Heinrich von Thünen Institute, Federal Research Institute for Rural Areas, Forestry and Fisheries, Braunschweig

Wood SN (2006a) Generalized additive models: an introduction with R. Chapman \& Hall/CRC Press, Boca Raton

Wood SN (2006b) Low-rank scale-invariant tensor product smooths for generalized additive mixed models. Biometrics 62(4):1025-1036. https://doi.org/10.1111/j.1541-0420.2006.00574.x

Wood SN (2006c) On confidence intervals for generalized additive models based on penalized regression splines. Aust N Z J Stat 48(4):445-464. https://doi.org/10.1111/j.1467-842X.2006. 00450.x 
Wood SN (2017) mgcv: mixed GAM computation vehicle with automatic smoothness estimations, R package version 1.8-18. https://cran.rproject.org/web/packages/mgcv/index.html

Zech W (1970) Nadelanalytische Untersuchungen über die Kalkchlorose der Waldkiefer (Pinus silvestris). J Plant Nutr Soil Sci (Z Pflanzenernähr Bodenkd) 125(1):1-16

Zierl B (2004) A simulation study to analyse the relations between crown condition and drought in Switzerland. For Ecol Manag 188(1-3):25-38. https://doi.org/10.1016/j.foreco.2003.07.019

Open Access This chapter is licensed under the terms of the Creative Commons Attribution 4.0 International License (http://creativecommons.org/licenses/by/4.0/), which permits use, sharing, adaptation, distribution and reproduction in any medium or format, as long as you give appropriate credit to the original author(s) and the source, provide a link to the Creative Commons licence and indicate if changes were made.

The images or other third party material in this chapter are included in the chapter's Creative Commons licence, unless indicated otherwise in a credit line to the material. If material is not included in the chapter's Creative Commons licence and your intended use is not permitted by statutory regulation or exceeds the permitted use, you will need to obtain permission directly from the copyright holder. 